\title{
Re-exploration of subjective well-being determinants: Full-model approach with extended cross-contextual analysis
}

\author{
Ki-Hoon Jun
}

\begin{abstract}
Despite the numerous studies on the determinants of subjective wellbeing (SWB), there are still under-researched areas as follows: a full-model approach allowing un-confounded and robust estimations, extension of cross-contextual approaches, and an account of recent changes in Hofstede value dimensions. The present study aims to overcome those limitations with analyses of 59 countries from 1981 to 2013, rendering the following main findings. Individual education's effect was methodologically affected by the reference category level of dummy variables. I found weak influence of GPRGE (governance, political rights, and gender equality) and individualism, which were associable with the ambivalent nature of intellectual autonomy. Regarding crosscontextual effects, I found that people from underdeveloped societies keep more to current pleasure, and that demand for welfare is higher in affluent and individualistic societies. A culture of uncertainty avoidance reduced the effect of national employment, because of its demotivating aspects in the workplace. Overall, variables related with hedonism, social relation, and wealth showed coherently strong effects, but social progress factors had weak relevance.
\end{abstract}

Keywords: life satisfaction, happiness, robust effects, cross-contextual approach, Hofstede value dimensions, social quality

\section{Introduction}

After first being discussed as an alternative to national GDP as a societal goal, subjective wellbeing (SWB) has surged as an important tool for the evaluation of national policies, making observable people's subjective reaction to the implementation of different policies (Dolan \& White, 2007; Donovan, Halpern, Sargeant, \& Britain, 2002; Helliwell \& Barrington-Leigh, 2010). As a result, "the empirical literature on happiness, life satisfaction and subjective wellbeing has virtually exploded in the last decade and a half" (Bjørnskov, 2008, p. 54). For instance, in 1990 only 111 studies on SWB were registered in the Web of Science, but that number had increased to 410 in 1998. By 2008, the number further tripled to 1240, and since 2011 over 1500 studies on SWB have been published on the database annually. In those numerous studies, a variety of domains across demographic, economic, social, and cultural sectors have been addressed as potential predictors of SWB. In view of these rich explorations, the scopes of SWB seem to have been fully explored, leaving few to be added. Nevertheless, there are still unexplored areas as follows.

The first limitation of previous SWB research is that, while predictors of various types have 
been discussed, very few studies have taken a full-model approach, failing to assure the effects ${ }^{\prime 1}$ robustness to confoundation. While a variable's effect instability is largely due to differences in control variables across studies (Bjørnskov, Dreher, \& Fischer, 2008, p. 167), the surest way to ensure robust and accurate estimation is the full model approach, which takes account of the widest range of control variables. This is important not only for empirical estimation, but also for theoretical developments on the nature of SWB. Researchers in SWB have differed in their views with respect to the relative importance and significance of each sector; for effective discussion among diverse stances, accurate estimation is essential. All this supports the full model approach as the only means to control the widest possible range of confounders. Despite such needs, hitherto, very few studies have addressed simultaneously economic, cultural, and demographic variables, and a broad range of social domains.

The second limitation of previous studies is a scarcity of cross-contextual approaches, although the importance of such approaches has been indicated already. In detail, (a) interaction involving national wealth, (2) cultural moderation on national social factors, and (3) the moderation of demographic variables by national social factors are the three main areas of crosscontextual approach that have been under-researched.

The last limitation of previous studies is that they have overlooked recent changes in national cultural values as predictors of SWB. While most studies on the value-SWB relationship have built on Hofstede's dimension system, all of them used the original framework that was constructed mainly during the 1970s, and thus they failed to capture subsequent cultural changes, as well as the effect of new Hofstede dimensions proposed after the mid-2000s. With all those respects, it is suggested that the existing literature has predicted SWB in the present by a limited range of past culture.

To overcome the aforementioned three limitations, the present study pursues the three aims as follows. The first aim is to take the full-model approach on the joint effects of demographic, wealth, cultural variables, and a broad range of social domains. The second aim is to extend the cross-contextual approach, with a focus on interaction involving national wealth, cultural moderation on national social factors, and demographic variables' moderation by national social factors. The last aim is to provide an account of up-to-date national culture as predictors of SWB, building on alternative data than Hofstede's original framework.

In the next section, I will give an overview of previous studies on the effect of demographic variables, national wealth, social factors, and value dimensions. Subsequently, the threefold limitation of previous studies is elaborated in detail, followed by the research design for this study, analyses and results, and implications. Because of limited space, the summary of results will be omitted.

Although not conventional in empirical studies, the present paper does not introduce hypotheses; it is simply impossible to set and state a hypothesis for the main and interaction effects of each of the numerous factors. Furthermore, most of the effects analyzed in this paper have been hypothesized in previous literature. Where this study replicates the same results as in previous studies, it is enough to re-state the previous studies' hypotheses and specify that they were supported. Where results differ from those of earlier studies, I will state my own possible explanations.

Meanwhile, two sets of variables are outside the present paper's interest. First, I will exclude surveyed attitude variables (e.g. tolerance), because the direction of causality is not clear - one might be happy because one is tolerant, but it is also possible that one is tolerant because one is

\footnotetext{
${ }^{1}$ In the present paper, 'effect' will always refer to 'effect on SWB', unless stated otherwise.
} 
satisfied with one's life. Second, personality traits (e.g., extraversion and neuroticism) are also not part of my concern, because they do not constitute constructs separate from national sociohistorical traits or value dimensions (Allik \& McCrae, 2004; Hofstede \& McCrae, 2004).

\subsection{Cognitive and emotional domains in SWB.}

Happiness, defined as emotional/affective SWB, is concerned with joy, contentment, and temporal mood; life satisfaction (hereafter LS), a cognitive component of SWB, deals with the evaluation of objective conditions and fulfillments (Diener, Oishi, \& Lucas, 2003, p. 405), and thus is more materialistic in nature (Haller \& Hadler, 2006; Helliwell, Barrington-Leigh, Harris, \& Huang, 2009) than is happiness.

For a better understanding of the mechanisms of SWB effects, the present study analyzes both happiness and LS. Considering that LS is more materialistic than is happiness, a variable's greater effect for LS should be explained by material conditions. If the effect is greater for happiness, in turn, it should be analyzed with more attention on other factors like social connectedness, attitudes, and emotional aspects.

\subsection{Previous findings: Consistencies and inconsistencies in determinants of SWB.}

The effects on SWB in previous studies have covered various domains of the national economy, social indicators, and value dimensions, and are presented in Table 1, following. Here I review each sector's effect significance in previous studies.

\subsubsection{Importance of national wealth and its variation across GDP levels.}

According to Clark and Senik's (2010: 73-75) review, studies prior to their research consistently supported national affluence's cross-sectional association with SWB. National wealth's longitudinal effect for a worldwide sample has been supported by Roca (2011) and Sacks, Stevenson, and Wolfers (2011).

Another issue is whether the income effect falls in richer countries, in line with the economic principle of diminishing marginal utility. This hypothesis was supported by Blanchflower's (2008, p. 33) and Inglehart, Foa, Peterson, and Welzel's (2008) studies, but not by the research of Sacks, Stevenson, and Wolfers (2010). In Helliwell (2008), the national wealth effect was rather higher in the OECD group, where most member countries are somewhat affluent.

\subsubsection{Social factors: Few consistent effects, and little support for the impact of democracy and inequality.}

Intuitively thinking, development in social indicators like democracy, increased rights, and equality would lead to greater societal SWB. Empirically, however, only the benefits of social capital (trust and membership ${ }^{2}$ ) and transparency (low corruption) have been consistently supported by all previous studies (Table 1 below). Excepting national employment rate, social domains in general do not make a significant contribution to SWB when economic and cultural variables are controlled.

\footnotetext{
2 They belong to social capital's subcomponents, according to the definition of Putnam, Leonardi, and Nanetti (1993).
} 
Table 1a. Significance and direction of SWB determinants in previous studies

\begin{tabular}{|c|c|}
\hline Variables & Previous studies supporting the effect \\
\hline \multicolumn{2}{|l|}{ Demographic variables } \\
\hline \multirow[t]{4}{*}{ Age } & Non-linear: Alesina, Di Tella, \& MacCulloch (2004), Feasel (2013), Helliwell (2002), Kim (2011), Rojas (2011), Tavits (2008) \\
\hline & Significantly positive: Abbott \& Wallace (2012), Flavin et al. (2010) \\
\hline & Significantly negative: Helliwell \& Putnam (2004) \\
\hline & Non-significant: Camfield, Guillen-Royo \& Velazco (2009) \\
\hline \multirow[t]{4}{*}{ Female } & Significantly positive: Abbott \& Wallace (2012), Alesina et al. (2004), Douhou \& Soest (2013), Feasel (2013), Flavin et al. (2010), Helliwell (2008), \\
\hline & Kim (2011), Tsai et al. (2011) \\
\hline & Significantly negative: Camfield et al. (2009), Salinas-Jiménez Artés \& Salinas-Jiménez (2010) \\
\hline & Non-significant: Helliwell \& Putnam (2004) \\
\hline \multirow[t]{3}{*}{ Education } & Non-linear: Helliwell (2002) \\
\hline & $\begin{array}{l}\text { Significantly positive: Blanchflower \& College (2005), Feasel (2013), Helliwell (2008), Helliwell \& Putnam (2004), Roca (2011), Salinas-Jiménez } \\
\text { et al. (2010), Tavits (2008), Tsai et al. (2011) }\end{array}$ \\
\hline & Non-significant: Abbott \& Wallace (2012), Camfield et al. (2009), Douhou \& Soest (2013), Flavin et al. (2010), Kim (2011) \\
\hline \multirow[t]{3}{*}{ Individual/household income } & Non-linear: Douhou \& Soest (2013) \\
\hline & $\begin{array}{l}\text { Significantly positive: Flavin et al. (2010), Feasel (2013), Helliwell (2008), Inglehart et al. (2008), Kim (2011), Salinas-Jiménez et al. (2010), Senik } \\
\text { (2004), Tsai et al. (2011) }\end{array}$ \\
\hline & Non-significant: Abbott \& Wallace (2012) \\
\hline Employed & $\begin{array}{l}\text { Significantly positive: Blanchflower \& College (2005), Douhou \& Soest (2013), Flavin et al. (2010), Feasel (2013), Helliwell (2002), Helliwell \& } \\
\text { Putnam (2004), Roca (2011), Tavits (2008), Tsai et al. (2011) } \\
\text { Non-significant: Camfield et al. (2009) }\end{array}$ \\
\hline Married & $\begin{array}{l}\text { Significantly positive: Abbott \& Wallace (2012), Alesina et al. (2004), Blanchflower \& College (2005), Feasel (2013), Flavin et al. (2010), Helliwell } \\
\text { (2002, 2008), Helliwell \& Putnam (2004), Kim (2011), Salinas-Jiménez et al. (2010), Tavits (2008), Tsai et al. (2011) }\end{array}$ \\
\hline Religiosity & Significantly positive: Feasel (2013), Flavin et al. (2010), Helliwell (2002) , Helliwell \& Putnam (2004), Kim (2011) \\
\hline Health & $\begin{array}{l}\text { Significantly positive: Argyle (1997), George \& Landerman (1983), Helliwell \& Putnam (2004), Morrison, Tay, \& Diener (2011), Okun \& George } \\
\text { (1984), Okun, Stock, Haring, \& Witter (1983) }\end{array}$ \\
\hline \multicolumn{2}{|l|}{ National economic factors } \\
\hline \multirow[t]{4}{*}{ National Income } & Non-linear: Helliwell (2002), Roca (2011) \\
\hline & Significantly positive: Hanssen (2011), Helliwell \& Putnam (2004), Inglehart et al. (2008), \\
\hline & Kim (2011), Minkov (2009), Roca (2011), Sacks, Stevenson. \& Wolfers (2011), Schyns (1998), Tavits (2008) \\
\hline & Non-significant: Diaz-Serrano \& Rodríguez-Pose (2012), Flavin et al. (2010), Helliwell (2008) \\
\hline \multirow[t]{2}{*}{ Economic Growth } & Significantly negative: Roca (2011) \\
\hline & Non-significant: Inglehart et al. (2008) \\
\hline \multirow[t]{2}{*}{ Inflation } & Significantly positive: Tavits (2008) \\
\hline & Significantly negative: Diaz-Serrano \& Rodríguez-Pose (2012), Hanssen (2011) \\
\hline
\end{tabular}


Table 1b. Significance and direction of SWB determinants in previous studies

\section{Variables \\ National economic factors}

Transparency

(Less corruption)

Democracy/Rights

Gender Equality

Distribution equality (lower inequality),

\section{Labor Union}

Membership

National Education

National Employment

Trust

\section{Cultural zones}

East Asia

Eastern Europe/Orthodox

Islamic

Latin America

\section{Value dimensions}

Individualism

\section{Masculinity}

PDI

UAI

IVR

\section{Previous studies supporting the effect}

Significantly positive: Diaz-Serrano \& Rodríguez-Pose (2012), Tavits (2008)

Significantly negative: Arrindell, Hatzichristou, Wensink, \& Rosenberg (1997), Helliwell (2008), Helliwell \& Putnam (2004) Non-significant: Knutsen (2005), Minkov (2009), Ott (2008, 2009), Roca (2011), Schyns (1998)

Significantly positive: Bjørnskov, Fischer, \& Dreher (2007)

Non-significant: Minkov (2009), Schyns (1998)

Significantly positive: Hanssen (2011), Tavits (2008)

Significantly negative: Roca (2011)

Non-significant: Helliwell \& Putnam (2004), Kim (2011), Knutsen (2005), Minkov (2009)

Significantly positive: Flavin et al. (2010)

Non-significant: Abbott \& Wallace (2012)

Significantly positive: Helliwell (2002), Helliwell \& Putnam (2004), Tov \& Diener (2008)

Non-significant: Helliwell (2002, 2008)

Significantly positive: Diaz-Serrano \& Rodríguez-Pose (2012), Flavin et al. (2010), Feasel (2013)

Non-significant: Alesina et al. (2004), Hanssen (2011)

Significantly positive: Abbott \& Wallace (2012), Diaz-Serrano \& Rodríguez-Pose (2012), Douhou \& Soest (2013), Flavin et al. (2010), Helliwell (2002), Helliwell \& Putnam (2004), Tsai et al. (2011)

Non-significant: Helliwell (2002)

Significantly negative: Feasel (2013), Knutsen (2005), Minkov (2009)

Significantly negative: Hanssen (2011)

Non-significant: Feasel (2013), Knutsen (2005)

Significantly positive: Knutsen (2005), Hanssen (2011), Helliwell (2002)

Significantly positive: Arrindell, Hatzichristou, Wensink \& Rosenberg (1997), Diener \& Suh (1997), Fischer \& Boer (2011), Larsen \& Eid (2008) Non-significant: Flavin et al. (2010), Schyns (1998)

Non-significant: Arrindell et al. (1997), Basabe et al. (2000)

Significantly negative: Arrindell et al. (1997), Basabe et al. (2000)

Significantly negative: Arrindell et al. (1997), Basabe et al. (2000) Non-linear: Minkov (2009)

Note: $\mathrm{SWB}=$ Subjective Well-Being. PDI = power distance. UAI = uncertainty avoidance. IVR = Indulgence versus Restraint. Among value dimensions, no previous study has dealt with long/short-term orientation's effect for SWB. Among value dimensions, no previous study has dealt with long/short-term orientation's effect for SWB. 
It is worth noting, in particular, that no previous study has supported the significant association of democracy with SWB. On the contrary, a negative effect was found by Inglehart et al. (2008) and Arrindell, Hatzichristou, Wensink, \& Rosenberg (1997). Inglehart et al. explained that during the years analyzed (at the beginning of the 1990s) many countries experienced a sudden transition to democracy, and their SWB was stable by its nature (p.270)3. In my view, this is not a sufficient explanation because according to the same logic, also other national domains than democracy should have had limited effects whenever any country experienced radical changes. Furthermore, in Arrindell et al. (1997) - another study in which the coefficient of democracy is negative, only one out of 36 countries (the former Yugoslavia) had experienced a transition to democracy during the years 1987-1993.

Inequality is another social variable whose effect does not stand out as being theoretically argued. The effect of greater inequality was detrimental to SWB only in Hanssen (2011) and Tavits (2008); it was otherwise non-significant (Helliwell \& Putnam, 2004; S. Kim, 2011; Knutsen, 2005; Minkov, 2009), and even positive in Roca (2011). With respect to inequality's possible association with SWB, Clark (2003) argued that inequality might bring aspiring effects; because when seeing those who were richer, people might believe that they could become rich like them in the future. Adaptation propensity (or treadmill effect) and comparison effect have been suggested as common explanations for both democracy and low inequality's lack of effect (Knutsen, 2005). Regardless of whether or not a society is equal and democratic, people will accept the social system as granted as time goes by. Therefore, the impact of social change on SWB is temporary, and after time passes people's SWB will return to previous levels. On the other hand, people compare their circumstances with those of their within-society neighbors, rather than with those of people in distant societies (Knutsen, 2005, p. 17). Following the same logic, however, other factors like national wealth also should have experienced limited effects, which simply is not the case. In this respect, adaptation theory and comparison reference cannot be sufficient explanations.

\subsubsection{Hofstede value dimensions}

Value dimension refers to organizational factors and attitudes which influence people's ideas about how things "ought to be" (Lonner, Berry, \& Hofstede, 1980). It was initially pioneered by Hofstede (Fischer, Vauclair, Fontaine, \& Schwartz, 2010, p. 138; Licht, Goldschmidt, \& Shalom, 2007 , p. 5; Snider, 2003, p. 24), whose original version of a value dimension framework includes the following dimensions.
Individualism: the culture of individualism emphasizes independence, achievement, uniqueness, and individual rights, while the culture of collectivism (low individualism) prioritizes in-group membership, loyalty, interdependence and belongingness. ${ }^{4}$
Power distance (PDI) refers to the social acceptance of unequal hierarchical relationship within an organization. It is important to note that such acceptance comes from societal members in a low position, not from the top.

\footnotetext{
${ }^{3}$ As evidence, Inglehart and colleagues provide another finding that the correlation between democracy and happiness fell from .74 in 1987 to .4 in 1993 and no further change occurred through to 2007. However, their bivariate correlation does not preclude that democracy since the 1990s no longer exerts positive influences on SWB, and that democracy prior to 1987 was highly correlated with SWB because of the wealth or other characteristics of earlier democratic countries, rather than of democracy itself.

${ }^{4}$ All value dimensions' introductions are quoted from Hofstede \& Jan (2011).
} 
Masculinity vs. femininity: masculine cultures put emphasis on performance, achievement, material success, power, and gender role differences; conversely, feministic cultures prioritize quality of life, mutual care, equality, and similarity in societal role between genders.

Uncertainty Avoidance (UAI): while people in high UAI cultures are highly sensitive to uncertainties and try to minimize risk through strict regulation, those in a low UAI culture are willing to accept uncertainties.

Among these four dimensions, individualism's social nature and its relationship with SWB have been the most discussed, with varying stances. It has been pointed out that individualism is crucial for SWB because it represents freedom, autonomy, and a greater number of choices (Diener \& Suh, 1997; Diener, Suh, Lucas, \& Smith, 1999; Larsen \& Eid, 2008). However, individualism might also feature negative aspects such as social isolation, loneliness, overreliance on materialism, and consumerism to escape from futility (Cushman, 1990; Schwartz, 2004, 2010). There also exists middle-ground stance that implies its moderated level is best, because in that condition autonomy and relatedness are balanced. While theoretical stances on individualism's social function diverge, empirical analyses have been inclined to its positive association with SWB (see Table 1 above).

Basabe et al. (2000) note the negative aspects of masculinity, PDI, and UAI. PDI legitimizes social inequality, causing anger at the societal level; masculinity causes more frequent negative emotions and lower social support because of excessive competitiveness and the prevalence of aggression; a high UAI culture's tighter formal rules and social control cause greater anxiety and negative emotions. Table 1 above shows that most previous empirical studies support Basabe et al. (2000)'s claims.

Lately, through co-research with Michael Minkov using World Value Survey (WVS) data for over 90 countries (Hofstede \& Minkov, 2010; Minkov, 2009), Hofstede added two more dimensions.

Indulgence vs Restraint (IVR): In cultures with a high degree of indulgence, free gratification of instinct-driven pleasure is allowed; in restraint cultures, hedonistic behavior is suppressed by strict norms (Minkov, 2009).

Long/Short-Term Orientation (LTO): in long-term oriented societies, pragmatic and future-oriented behaviors like saving, persistence, and self-adaptation to changing circumstances, are encouraged; in short-term oriented societies, past and present elements such as national pride, tradition, a person's 'face', and social obligations are more valued (Hofstede \& Minkov, 2010).

Being proposed lately, however, they have been little discussed in relation to SWB, except that Minkov (2009) found IVR's strong effect for happiness.

To summarize, previous findings are inclined to support individualism's positive association with SWB, and the negative side of masculinity, PDI, and UAI. For IVR and LTO, few empirical examinations have been done because they came to light no earlier than the middle of the first decade of the present century. 
Table 2: Three flows of cross-contextual approaches for subjective wellbeing, in previous studies

\begin{tabular}{|c|c|c|c|}
\hline Categories & Sub-categories & Authors & Effects' variation \\
\hline \multirow{5}{*}{$\begin{array}{l}\text { Interactions involving } \\
\text { national wealth }\end{array}$} & \multirow{3}{*}{$\begin{array}{l}\text { Social factors moderation by } \\
\text { national income groups }\end{array}$} & Helliwell (2008) & Perceived transparency and trust: highera in OECD group \\
\hline & & Ott (2009) & Democracy and state capacity: higher in richer countries \\
\hline & & Schyns (1998) & Gender equality and democracy: higher in richer countries \\
\hline & $\begin{array}{l}\text { Cultural value's moderation } \\
\text { by income }\end{array}$ & Schyns (1998) & Individualism: higher in richer countries \\
\hline & $\begin{array}{l}\text { Income's moderation by } \\
\text { value dimensions }\end{array}$ & Arrindell et al. (1997) & $\begin{array}{l}\text { Affluence: higher in feministic culture where welfare system for quality of life is more } \\
\text { demanded }\end{array}$ \\
\hline \multirow[t]{7}{*}{$\begin{array}{l}\text { Moderation of national } \\
\text { social factors by } \\
\text { demographic traits }\end{array}$} & \multirow[t]{7}{*}{$\begin{array}{l}\text { National social factors' } \\
\text { moderation by individual } \\
\text { traits }\end{array}$} & $\begin{array}{l}\text { Alesina, Di Tella, \& MacCulloch } \\
\text { (2004) }\end{array}$ & $\begin{array}{l}\text { In American sample, lower economic inequality: higher for the right-wing and rich } \\
\text { group; lower national unemployment: higher for the left-wing. } \\
\text { In European sample: lower economic inequality: higher for the left and poor group; } \\
\text { lower national unemployment rate: higher for the poor group. }\end{array}$ \\
\hline & & $\begin{array}{l}\text { Bjørnskov, Dreher, \& Fischer } \\
\text { (2008) }\end{array}$ & $\begin{array}{l}\text { Government fractionalization, republic regime, and growth stability: higher for the } \\
\text { right-wing lower income group }\end{array}$ \\
\hline & & & $\begin{array}{l}\text { National income, investment price, and compound growth rate: higher for the left-wing } \\
\text { high income }\end{array}$ \\
\hline & & & Regulatory quality: higher for the right-wing and high income group \\
\hline & & & $\begin{array}{l}\text { Governance and lack of corruption: higher for the left-wing, and low/middle income } \\
\text { group }\end{array}$ \\
\hline & & Flavin, Pacek, \& Radcliff (2010) & National labor union density: higher among low-income individuals \\
\hline & & Joshanloo \& Weijers (2013) & Lower inequality: higher among non-religious people \\
\hline $\begin{array}{l}\text { Moderation of national } \\
\text { social factors by } \\
\text { demographic traits }\end{array}$ & $\begin{array}{l}\text { National social factors' } \\
\text { moderation by individual } \\
\text { traits }\end{array}$ & Weijers \& Joshanloo (2013) & Gender equality: higher for non-religious people \\
\hline \multirow{7}{*}{$\begin{array}{l}\text { Variation of } \\
\text { demographic effects } \\
\text { across national income } \\
\text { groups and cultural } \\
\text { zones }\end{array}$} & \multirow{7}{*}{$\begin{array}{l}\text { Demographic variables' } \\
\text { moderation by National } \\
\text { income level } \\
\text { Demographic moderation by } \\
\text { cultural zones }\end{array}$} & Helliwell (2008) & Marriedness: In OECD \\
\hline & & & Individual education and church attendance: higher in OECD \\
\hline & & Swift et al. (2014) & Younger age: higher in poorer countries \\
\hline & & Bonini (2007) & $\begin{array}{l}\text { Marriedness: less effects in South Asia and Sub-Saharan Africa, former socialist zone } \\
\text { Individual income: higher in former socialist zone, but lowest in South Asia and Sub- } \\
\text { Saharan Africa }\end{array}$ \\
\hline & & Helliwell (2008) & Marriedness: no effect in Latin America \\
\hline & & & Individual high education: no effect in English-speaking zone \\
\hline & & Swift et al. (2014) & Being female: higher in Latin America \\
\hline
\end{tabular}

a Higher means that the variable has higher or stronger effect in stated moderation groups 


\subsection{Cross-contextual approaches: Interaction models and group-wise analyses}

The priorities of different life domains for SWB vary across countries even when countries' economic development levels are similar (Camfield, 2012, p. 404).

In fact, it is not a new argument to emphasize the importance of considering crosscontextuality in SWB predictors (Bonini, 2007; Fischer \& Boer, 2011; Howell \& Howell, 2008; Jorgensen, Jamieson, \& Martin, 2010; Oishi, Diener, Lucas, \& Suh, 1999; Welzel \& Inglehart, 2010). To empirically deal with such cross-contextuality, there are two strategies. One is case-wise comparison - comparing predictors' effects across different national or cultural groups, which differ in social, economic, or cultural contexts. The other is the statistical moderation approach - that is, to introduce cross-products between a variable of interest and a context variable. Between the two strategies, most cross-contextual studies have taken a statistical interaction approach, dealing with three types of moderating effects: interactions involving national income, variation of national social effects across demographic groups, and variation of demographic effects across national income groups and cultural zones. They are summarized in Table 2 above.

\subsection{Limitations of previous studies}

Despite the fact that a wide variety of variables across demographic, economic, social, and cultural domains have been repeatedly addressed in the previous literature, there remain unexplored facets in national SWB determinants. They are: (a) diverse ranges of cross-contextual or moderational approach, (b) full-model approach co-addressing demographic, economic, and cultural predictors, and a broad range of social factors, in order to enable each predictor's accurate estimation without mutual confounding, and (c) taking account of the recent changes in Hofstede's value system when measuring its relationship with SWB.

\subsubsection{Temporal validity of value dimensions}

All previous studies addressing the effect of Hofstede's dimensions of individualism, masculinity, PDI, and UAI have relied on Hofstede's original data from 1967-1973, or archival data covering the 1990s. Studies that have analyzed SWB after the 1990s suffer a large time gap between value dimensions and SWB. This would not be a problem if national culture changes little over time, but there is counter-evidence to this assumption. According to the abundant literature introduced in Taras, Steel, and Kirkman's (2012) empirical meta-analysis, a nation's values can change even within short periods. Based on their meta-analysis, Taras et al. extracted decade-wise scores from the 1980s to the first decade of the 2000s, and found evidence that national culture does alter substantially over time. For any of the four dimensions, the degree of correlation between original scores and since-2000s scores was no more than .75 (p. 338). Furthermore, they also found that during the 1970s the United States and South America were sharply contrasted in the degree of individualism and PDI, but since 2000 such cultural difference has disappeared or reversed (p. 339). With Taras et al.'s findings on national culture's changeability, predicting the current SWB from the past culture will render limited validity.

\subsubsection{Joint account for all sectors: Robust estimation without confounding}

Helliwell, Layard, and Sachs (2012, p. 64) and Helliwell (2002, p. 5) pointed out that social or cultural factors' effects could be confounders for national wealth. As evidence, they showed that when social factors were controlled, the wealth effect coefficient for LS fell from .81 to below .30. In the same context, when estimating any of the following domains - demographic, economic, social, and cultural factors - the others remain as possible confounders to be controlled. Solving 
confounding is also important to assure robust effects (Bjørnskov et al., 2008, p. 167). In fact, we say an effect lacks robustness whenever it is altered by controlled or uncontrolled confounders.

For those reasons, an effective way for accurate and robust estimation is to establish models co-including variables of different domains which might confound each other. In other words, the effects of wealth, demographic, cultural and broad-ranged social factors can be estimated robustly only when all their effects are estimated together and simultaneously; otherwise, one would remain as a confounder of the others. In short, a full-model approach is needed for robust and precise estimation.

Notwithstanding, few studies hitherto have effectively dealt with this need. Among previous studies which seem to be exceptions, Feasel (2013) missed social capital and cultural value dimensions, while Arrindell et al. (1997) and Schyns (1998) missed demographic variables, analyzing only at the national level. Meanwhile, Minkov (2009) included only six national social indicators, while Helliwell (2002) and Helliwell, Huang, \& Harris (2009) used only survey-based subjective variables for social domains, and Helliwell \& Putnam (2004) and Helliwell (2008) took only government quality and trust as social predictors.

\subsubsection{Unexplored areas in cross-contextual approaches}

With detailed findings in the studies reviewed above, at first glance the cross-contextual approach seems now fully explored. Compared with main effects studies, however, the number of studies involved is quite small. When looking at those studies more carefully, furthermore, there remain unexplored areas as follows.

One under-researched area in the cross-contextual approach is that involving national wealth - the interaction effects between national wealth and national-level social factors, and those between national wealth and cultural variables. While the types of moderation involving national wealth have been analyzed in both directions ${ }^{5}$, the range of socio-cultural factors is far from being exhaustive, including only two of the six Hofstede value dimensions (individualism and masculinity) and five national social variables (transparency, trust, gender equality, democracy, and state capacity). Taken together, the cross-contextual approach can be further developed by analyzing national income's interaction with a broader range of national sociocultural elements.

Cultural moderation of national social effects has been also under-researched. Regarding moderating effects by cultural zones, only perceived transparency and trust have been addressed by Helliwell (2008).

Regarding moderation by national religion, likewise, only the effects of economic inequality (Joshanloo \& Weijers, 2013) and gender inequality (Weijers \& Joshanloo, 2013) have been examined as its objects. Those variables are obviously far from being able to cover the exhaustive range of social domains. Furthermore, no study has dealt with social domains' moderation by cultural value dimensions.

Another unexplored cross-contextual approach regards the effect variation of multiple demographic variables by national social factors. At first glance it might not seem so, since Di Tella and MacCulloch (2004), Bjørnskov, Dreher, and Fischer (2008), and Flavin, Pacek, and Radcliff (2010) did compare national socio-economic indicators and cultural zones' relevance across three categories of demographic groups — sex, income level, and political ideology (Table

\footnotetext{
${ }^{5}$ In Schyns (1998) and Ott (2009), the national socio-economic effects were compared by national income groups; in their studies, obviously, national wealth was a moderator, not the variable moderated. In Arrindell et al. (1997), on the contrary, national wealth's relationship with SWB was the object of the moderating effect of two cultural value dimensions.
} 
2 above). While they dealt with national social variables' moderation by three types of demographic groups, their analyses do not tell us about the heterogeneity of the individual traits' relevance by national social contexts. Furthermore, their study's moderating demographic variables were limited to individual/household income, sex, and political orientation. Hitherto no study has dealt with moderation by other demographic variables like marital status, religiousness, employment status, and education level, or by interactions between national noneconomic and non-cultural social domains. By taking account into the national effects variation by more diverse demographic factors in the same model, further developments can be made on the cross-contextual scope for SWB studies.

To sum up, although the need for a cross-contextual approach has been repeatedly indicated, there are still a lot to be explored. In detail, there are three especially under-researched areas (a) interaction between national wealth and national socio-cultural elements, (b) national noneconomic social factors' moderation by culture, and (c) national social factors' moderation by diverse demographic traits besides sex, income level, and political ideology.

\section{Aims and design of the present research}

The present paper aims to overcome the limitations in previous SWB literature in three ways: (a) reflecting recent changes in national cultural values as predictors of SWB, (b) establishing full models, allowing robust and un-confounded estimations, with simultaneous insertion of national wealth, culture, and sufficiently broad social domains, (c) extension of cross-contextual models, by newly taking into account interactions involving national wealth, cultural moderation on national social domains, and diverse demographic traits' moderation by national social contexts.

For those purposes, I will conduct analyses with a WVS sample of 59 countries covering the years from 1981 to 2013, using all observations where either happiness or LS was present. From WVS, two SWB components are chosen. Meanwhile, two types of predictors were picked from WVS. The first one is demographic variables, which includes age, sex, education, individual income, religiousness, employment status, matrimonial status, and health; the second one is social survey variables, including trust, institutional confidence, membership, and satisfaction with democracy. Those individual-level observations are merged with the same year or the latest available prior year's data of national logged GDP, objective national social indicators, and cultural value dimensions. The information about objective social indicators and value dimensions is described in the next sub-sections of this section.

With those predictors, I analyze both LS and happiness, for richer explanations on the nature of found effects - in detail, whether the effects are more linkable with objective and material conditions (elements associated with LS), or with people's changed attitudes, emotions, and social connectedness (elements associated with happiness).

\subsection{Value dimensions: Use of alternative data to account for national cultural change}

Unlike all the relevant reviewed studies, I will use Taras et al.'s work for individualism, masculinity, PDI, and UAI, and draw on Hofstede's later data for LTO and IVR, in an effort to take into account national cultural changes that occurred after the 1970s. A caveat of using Taras et al.'s data is that some of subject units were international regions, for which it is not always appropriate to apply the same regional score to all sub-regional countries. That is because, within regions like South America the national cultures are certainly heterogeneous, and such variation is not counted in Taras et al.'s data. In turn, however, this does not mean that using Hofstede's old data is better just because all of its units are countries. Analyzing today's SWB with data from 
a past culture is likely to cause greater bias, which might raise more doubts on correlated economic and social effects in the same model, because of confoundation.

Therefore, I will persist in using Taras et al.'s data, despite some expected discrepancy between international regional scores and the real culture of each nation within a region. However, I admit that there is a need to minimize that discrepancy. For that reason, the scores for Africa, the Arab region, the Caribbean, Central America, and South America will be applied only to countries which were included in Taras et al.'s meta-analysis. However, the scores of the other, smaller, regions - the former Yugoslavia, Asian USSR, Baltic USSR, Slavic USSR, are applied to all countries in those regions, including those Taras et al. did not meta-analyze - each of those regions consists of less than six countries, which are expected to be both geographically and culturally close to each other ${ }^{6}$.

For the two newly proposed dimensions (LTO and IVR), meanwhile, I use Hofstede's lateversion data. While those dimensions were not tackled by Taras et al., Hofstede's data is enough to measure their current status because it is based on the surveys conducted during the 2000s (Minkov \& Hofstede, 2010; Minkov, 2009).

\subsection{Full Model with parsimony: Clustering national social variables}

In establishing the full model approach, one important issue is how to cover the wide range of social domains with a small number of variables. There are so many social sectors to be covered, but introducing many social indicators in the same model is problematic. It will be too complicated to discuss so many variables' main and interaction effects within limited space for the present paper. Furthermore, multiple social indicators can be bundled into a single dimension when their concepts are mutually related, even if not identical (e.g. World governance indicators in Langbein \& Stephen (2008)). On the other hand, inserting those variables in the same model will cause inconsistency in findings (Fischer, 2010, p. 2). All those respects support the need and legitimacy of obtaining a reduced number of dimensions, from many indicators which cover the full range of social domains drawn on Yee and Chang (2009)'s Social Quality framework, where four social dimensions were extracted from 19 indicators. For use for SWB research, it has some merits as follows. First, it is theoretically linked with SWB, since it is defined as people's ability to participate in community life while their potential and well-being are supported from social environments (Beck, 2001). Secondly, Yee and Chang's framework consists of only 19 variables to favor the parsimony, and those composing variables are largely coincident with previous studies' SWB predictors that were reviewed above. For those reasons, I adapt Yee and Chang's Social Quality framework as a tool for clustering social predictors of SWB.

\footnotetext{
${ }^{6}$ While I decided to rely on Taras et al.'s longitudinal data reflecting updated national culture, there are two exceptions: Poland's score for the first year of all four value dimensions (1989), and Vietnam's PDI for both years of survey (2001 and 2006) have come from Hofstede's original dimensions.
} 
Table 3. Source: Social variables

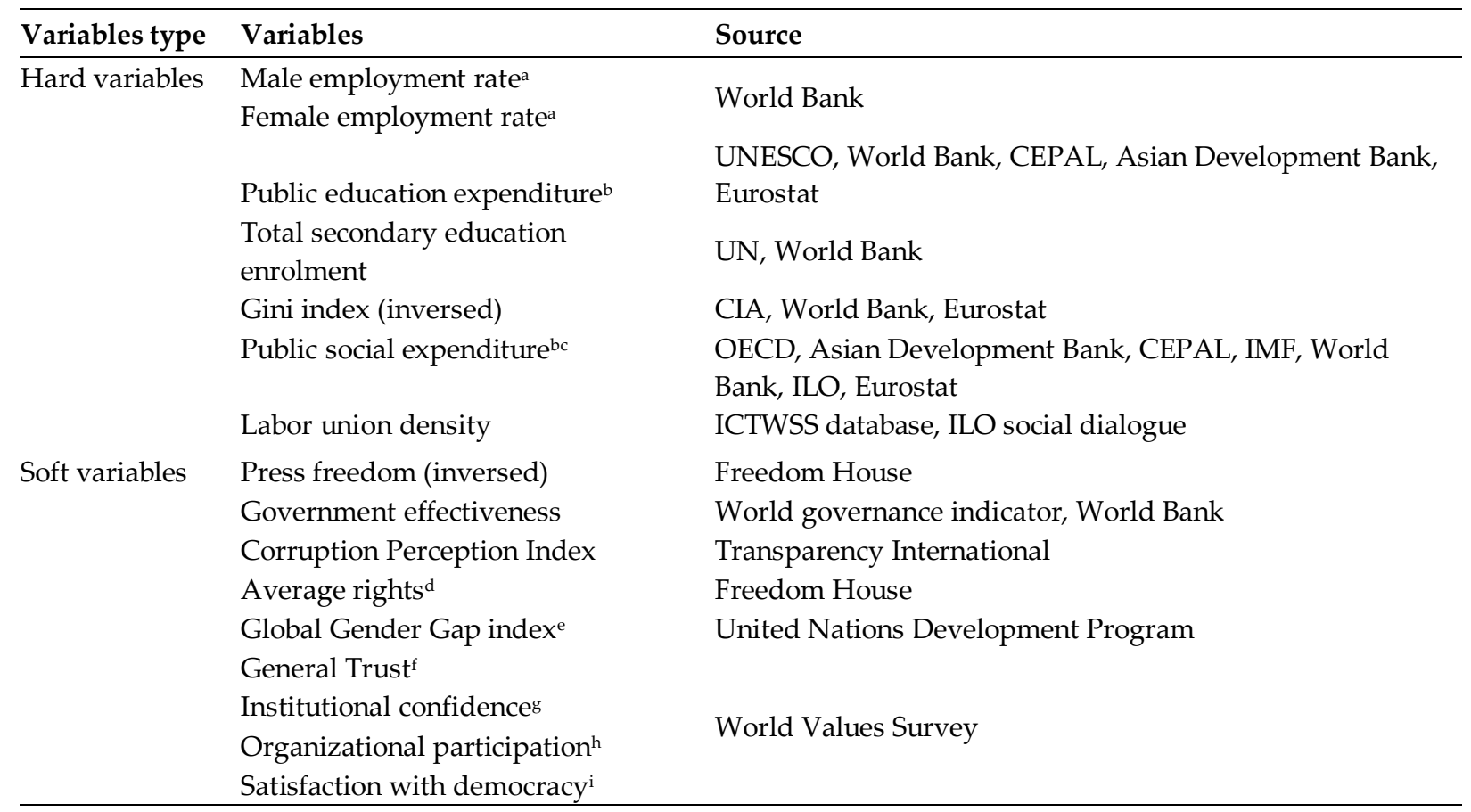

a Ratio to the population over +15. ${ }^{\mathrm{b}}$ Rate per GDP. c Since survey sources differ in included sectors of public spending (e.g. education, protection, pension, health, etc.), merely merging multiple sources without adjustment will cause serious distortions; to avoid such a problem, I count only public spending on social protection and security; when the raw scores contain other sectors like education or health, I subtracted those sectors' spending rates from the raw scores, prior to use for subsequent analyses. ${ }^{\mathrm{d}}$ Combined measure of political rights and civil liberties. ${ }^{\mathrm{e}}$ In Yee and Chang (2009)'s framework, the gender empowerment measure was used as a parameter for gender equality, but it is no longer published since 2010. ${ }^{\mathrm{f}}$ For the question on whether most people can be trusted, coded as one for yes, and zero for no. $\mathrm{g}$ While survey sources differed in the raw scale, all of them were adjusted to 1-4 by linear transformation. ${ }^{\mathrm{h}}$ If the respondents are engaged in any organization for active/inactive or voluntary works, coded as one; otherwise, coded as zero. ${ }^{i} 1-4$ ordinal scale.

Following Yee and Chang's suggestion (p. 159)7, I cluster hard and soft variables separately. Meanwhile, from the list of Yee and Chang's social variables, I exclude pension replacement which is unavailable in most non-OECD countries, along with the voter turnout that has been little researched, which has been little researched in previous SWB studies. The remaining variables are listed in Table 3 above.

After merging both subjective and objective social indicators, I performed the principal component analyses separately for hard and soft variables, as suggested by Yee and Chang. All analyzed social variables were clustered into four factors, as presented in the Table 4.

\footnotetext{
7 The sources of social quality variables, prior to conducting principal component analysis, are listed in Table 1 above.
} 
Table 4. Principal Component Analysis (PCA) for social variables

\begin{tabular}{lc}
\hline Variables & Loadings \\
\hline Hard variables & .686 \\
Component 1 - National employment & .606 \\
$\quad$ Female employment rate & .277 \\
$\quad$ Male employment rate & .520 \\
$\quad$ Labor union density & .511 \\
Component 2 - Edu/Welfare & .473 \\
$\quad$ Public social expenditure & .269 \\
Total secondary enrolment rate & \\
Public education expenditure & .493 \\
Gini index (inversed) & .475 \\
Soft variables & .470 \\
Component 3 - GPRGE & .456 \\
$\quad$ Press freedom (inversed) & .301 \\
Government effectiveness & .624 \\
Average rights & .591 \\
TI CPI & .343 \\
Global gender gap index & .334 \\
\hline
\end{tabular}

Note: Prior to conducting PCA, the national social variables had been merged with national wealth, cultural value dimensions data, and World Value Survey. Only countries having listwise scores of Hofstede's six dimensions and WVS's observations where either happiness or life satisfaction was available, were taken for PCA estimation and all the subsequent analyses in the present paper. The component scores were extracted by averaging the standardized values of clustered variables, without weighting on variables with higher loading; giving all variables the same degree of importance is in line with the comprehensive full-model approach in this paper. Edu/Welfare = education and welfare factor at national level. GPRGE = governance, political rights, and gender equality. TI CPI = Transparency International's corruption perception index.

After combining all social indicators, I performed principal component analysis. Based on the results, the components were extracted by averaging standardized values of social variables. In the present paper, the components will be named with the following terms.

National employment: the overall environment of national employment; it comprises male, female employment rate, and labor union density.

Education and Welfare (hereafter Edu/Welfare): encompasses education, public expenditure, and economic inequality.

Governance, political rights and gender equality (hereafter GPRGE): this factor embraces the concept of governance, political freedom, and gender equality.

Social capital: this factor comprises participation, satisfaction with democracy, general trust, and institutional confidence. Clustering those variables into the single concept of social capital is in line with its definition by Putnam (1994).

By reducing social variables to four factors, most previously discussed social determinants of SWB can be analyzed at once, and the number of main and interaction terms is small enough to be interpreted in this paper. After clustering social variables, Table 5 below presents summary statistics on all predictors for subsequent analyses. 
Table 5. Descriptive statistics

\begin{tabular}{|c|c|c|c|c|c|}
\hline Variables & $\mathbf{N}$ & Mean & Std. dev. & Minimum & Maximum \\
\hline \multicolumn{6}{|l|}{ SWB } \\
\hline Happiness & 235893 & 3.054 & 0.740 & 1 & 4 \\
\hline Life Satisfaction & 239396 & 6.662 & 2.407 & 1 & 10 \\
\hline \multicolumn{6}{|l|}{ Demographic variables ${ }^{a}$} \\
\hline Age/10 & 238706 & 4.183 & 1.642 & 14 & 99 \\
\hline Sex $($ male $=1)$ & 239832 & 0.479 & 0.500 & 0 & 1 \\
\hline Individual income $e^{b}$ & 216294 & 1.655 & 0.706 & 1 & 3 \\
\hline Education ${ }^{c}$ & 208138 & 2.723 & 0.831 & 1 & 4 \\
\hline Employed & 242551 & 0.531 & 0.499 & 0 & 1 \\
\hline Married & 242551 & 0.637 & 0.481 & 0 & 1 \\
\hline Religiosity $^{\mathrm{d}}$ & 242551 & 0.651 & 0.477 & 0 & 1 \\
\hline Healthe & 233784 & 0.656 & 0.475 & 0 & 1 \\
\hline \multicolumn{6}{|l|}{ SEFs } \\
\hline Log GDP & 240092 & 8.581 & 1.411 & 5.573 & 11.333 \\
\hline Employment & 241279 & -0.021 & 0.747 & -2.161 & 2.403 \\
\hline Edu/Welfare & 242551 & -0.003 & 0.740 & -1.782 & 2.172 \\
\hline GPRGE & 242551 & -0.009 & 0.873 & -1.710 & 1.608 \\
\hline Social capital & 241948 & 0.014 & 0.653 & -2.647 & 2.425 \\
\hline \multicolumn{6}{|l|}{ Value dimensions } \\
\hline Individualism & 242551 & -0.112 & 0.676 & -1.580 & 1.790 \\
\hline Masculinity & 242551 & -0.069 & 0.534 & -1.460 & 1.730 \\
\hline PDI & 242551 & 0.027 & 0.608 & -1.380 & 1.360 \\
\hline UAI & 242551 & 0.240 & 0.669 & -1.590 & 1.710 \\
\hline LTO & 242551 & 0.125 & 1.074 & -1.602 & 2.233 \\
\hline IVR & 242551 & 0.015 & 1.002 & -1.820 & 1.967 \\
\hline
\end{tabular}

Note: $N$ in pairwise $=242551.59$ countries. ${ }^{a}$ Among demographic variables, only age is continuous variable; individual income: three-step; individual education: four-step; sex, employed, married, religiosity, and health: binary variables. bIt was recoded from original 10-step to three-step as follows: from 1-4 to 1, 5-7 to 2, 8-10 to 3 . ${ }^{c} 1=$ primary incomplete, 2 = primary complete, $3=$ secondary complete, $4=$ tertiary or higher degree. ${ }^{\mathrm{d} C r i t e r i o n}$ set for religiosity: membership, participation, or service attendance in WVS survey. eFive-step health variable in WVS was recoded to become a binary on e: $1=$ very good or good, $0=$ fair, poor, or very poor status. $S W B=$ subjective wellbeing. $S E F s=$ national socioeconomic factors. $\mathrm{Edu} /$ Welfare = national-level factor of education and welfare. GPRGE $=$ governance, political rights, and gender equality. $\mathrm{PDI}=$ power distance. $\mathrm{UAI}=$ uncertainty avoidance. $\mathrm{LTO}=\mathrm{long} /$ short-term orientation. $\mathrm{IVR}=$ indulgence versus restraint.

\subsection{Estimator method}

All models for LS, which is a continuous variable, are estimated with multilevel regression with robust standard errors. For happiness, which is a four-step ordinal variable, all models will be estimated with ordinal logistic regression with robust standard errors. Unlike normal multilevel methods, however, neither random intercept nor random slope will be included; because random intercepts are actually equivalent to group mean, and they are already accounted for by national variables. Likewise, random slopes correspond to the cross-level interactions, and this is in turn already covered by interaction terms between demographic variables and national SEFs.

For age, national wealth, and individualism, whose nonlinear effect has been discussed in the previous literature, both their linear and non-linear term will be included at the same time. Meanwhile, prior to subsequent analyses, social quality factors and value dimensions are standardized. Besides, age variable is divided into one tenth and centered, to prevent collinearity between linear, quadratic, and interaction effects. 


\section{Results and Discussions}

Table 6 and Table 7 below display model series 1 and 2 for happiness, while Table 8 and Table 9 below present model series 3 and 4 for LS. In model series 2 and 4 , each SEF interacts with all the other predictors.

Table 6. Happiness models, no interaction terms

\begin{tabular}{|c|c|c|c|c|}
\hline & Model 1a & Model 1b & Model 1c & Model 1d \\
\hline \multicolumn{5}{|l|}{ Demographic variables $^{a}$} \\
\hline Age $/ 10$ & $-0.107^{* * *}$ & $-0.089^{* * *}$ & $-0.089^{* * *}$ & $-0.095^{* * *}$ \\
\hline$(\text { Age } / 10)^{2}$ & $0.054^{* * *}$ & $0.057^{* * *}$ & $0.056^{* * *}$ & $0.054^{* * *}$ \\
\hline Sex $($ male $=1)$ & $-0.143^{* * *}$ & $-0.159^{* * *}$ & $-0.161^{* * *}$ & $-0.153^{* * *}$ \\
\hline Individual income & $0.281^{* * *}$ & $0.294^{* * *}$ & $0.297^{* * *}$ & $0.274^{* * *}$ \\
\hline Education ${ }^{\mathrm{b}}$ & $0.01 \mathrm{f} 3.20$ & $0.050^{* * *}$ & $0.046^{* * *}$ & $0.043^{* * *}$ \\
\hline Employed & $-0.050^{* * *}$ & $-0.023^{*}$ & $-0.027^{*}$ & $-0.063^{* * *}$ \\
\hline Married & $0.519^{* * *}$ & $0.586^{* * *}$ & $0.581^{* * *}$ & $0.574^{* * *}$ \\
\hline Religiosity & $0.288^{* * *}$ & $0.241^{* * *}$ & $0.235^{* * *}$ & $0.207^{* * *}$ \\
\hline Health & $1.137^{* * *}$ & $1.105^{* * *}$ & $1.104^{* * *}$ & $1.084^{* * *}$ \\
\hline \multicolumn{5}{|l|}{ SEFs } \\
\hline Log GDP & $0.137^{* * *}$ & & -0.004 & $0.033^{* * *}$ \\
\hline $\log \mathrm{GDP}^{2}$ & $0.023^{* * *}$ & & $0.034^{* * *}$ & $0.009^{* *}$ \\
\hline Employment & $0.080^{* * *}$ & & & $0.140^{* * *}$ \\
\hline Edu/Welfare & $-0.312^{* * *}$ & & & $-0.038^{* * *}$ \\
\hline GPRGE & $0.258^{* * *}$ & & & $-0.049^{*}$ \\
\hline Social capital & $0.203^{* * *}$ & & & $0.198^{* * *}$ \\
\hline \multicolumn{5}{|l|}{ Value Dimensions } \\
\hline Individualism & & -0.013 & $-0.024^{* *}$ & $-0.016^{*}$ \\
\hline Individualism $^{2}$ & & $-0.057^{* * *}$ & $-0.063^{* * *}$ & $-0.063^{* * *}$ \\
\hline Masculinity & & $0.064^{* * *}$ & $0.075^{* * *}$ & $0.098^{* * *}$ \\
\hline PDI & & $-0.015^{*}$ & $-0.029^{* * *}$ & $-0.067^{* * *}$ \\
\hline UAI & & $-0.076^{* * *}$ & $-0.072^{* * *}$ & $-0.048^{* * *}$ \\
\hline LTO & & $0.044^{* * *}$ & $0.035^{* * *}$ & $-0.016^{*}$ \\
\hline IVR & & $0.591^{* * *}$ & $0.584^{* * *}$ & $0.559^{* * *}$ \\
\hline Cut-point 1 & $-1.949^{* * *}$ & $-1.966^{* * *}$ & $-1.925^{* * *}$ & $-2.116^{* * *}$ \\
\hline Cut-point 2 & $0.191^{* * *}$ & $0.180^{* * *}$ & $0.222^{* * *}$ & 0.047 \\
\hline Cut-point 3 & $2.994^{* * *}$ & $3.038^{* * *}$ & $3.083^{* * *}$ & $2.939^{* * *}$ \\
\hline Log-likelihood & -174929 & -172800 & -172694 & -171426 \\
\hline
\end{tabular}

Note: $N=175639$. Ordinal logistic regression with robust standard errors. a Among demographic variables, only age is a continuous variable; individual income: three-step; individual education: four-step; sex, employed, married, religiosity, and health: binary variables. ${ }^{b}$ Education: 1 = primary incomplete, 2 = primary complete, $3=$ secondary complete, 4 = tertiary or higher complete. SEFs = national socio-economic factors. Edu/Welfare = national-level factor of education and welfare. GPRGE = governance, political rights, and gender equality. PDI = power distance. UAI = uncertainty avoidance. LTO = long/short-term orientation. IVR = indulgence versus restraint.

${ }^{*} p<.05^{* *} p<.01{ }^{* * *} p<.001$ 
Table 7a. Happiness models, with moderating effects

\begin{tabular}{|c|c|c|c|c|c|}
\hline & $\begin{array}{c}\text { Model 2a: } \\
\text { IV }^{\mathrm{a}}=\text { Log GDP }\end{array}$ & $\begin{array}{c}\text { Model 2b: } \\
\text { IV = Employment }\end{array}$ & $\begin{array}{c}\text { Model 2c: } \\
\text { IV= Edu/Welfare }\end{array}$ & $\begin{array}{c}\text { Model 2d: } \\
\text { IV = GPRGE }\end{array}$ & $\begin{array}{c}\text { Model 2e: } \\
\text { IV = Social capital }\end{array}$ \\
\hline \multicolumn{6}{|c|}{ Main effects } \\
\hline \multicolumn{6}{|c|}{ Demographic variables ${ }^{b}$} \\
\hline Age/10 & $-0.089^{* * *}$ & $-0.100^{* * *}$ & $-0.091^{* * *}$ & $-0.093^{* * *}$ & $-0.092^{* * *}$ \\
\hline$(\text { Age } / 10)^{2}$ & $0.054^{* * *}$ & $0.054^{* * *}$ & $0.056^{* * *}$ & $0.053^{* * *}$ & $0.053^{* * *}$ \\
\hline Sex & $-0.162^{* * *}$ & $-0.163^{* * *}$ & $-0.157^{* * *}$ & $-0.161^{* * *}$ & $-0.155^{* * *}$ \\
\hline Income level & $0.280^{* * *}$ & $0.276^{* * *}$ & $0.277^{* * *}$ & $0.292^{* * *}$ & $0.277^{* * *}$ \\
\hline Education ${ }^{c}$ & $0.046^{* * *}$ & $0.042^{* * *}$ & $0.038^{* * *}$ & $0.039^{* * *}$ & $0.049^{* * *}$ \\
\hline Employed & $-0.047^{* * *}$ & $-0.065^{* * *}$ & $-0.059^{* * *}$ & $-0.045^{* * *}$ & $-0.062^{* * *}$ \\
\hline Married & $0.591^{* * *}$ & $0.577^{* * *}$ & $0.585^{* * *}$ & $0.594^{* * *}$ & $0.570^{* * *}$ \\
\hline Religious & $0.166^{* * *}$ & $0.190^{* * * *}$ & $0.192^{* * *}$ & $0.148^{* * *}$ & $0.214^{* * *}$ \\
\hline Health & $1.076^{* * *}$ & $1.076^{* * *}$ & $1.086^{* * *}$ & $1.077^{* * *}$ & $1.081^{* * *}$ \\
\hline \multicolumn{6}{|l|}{ SEFs } \\
\hline Log GDP & $0.184^{* * *}$ & $0.087^{* * *}$ & $0.047^{* * *}$ & $0.079^{* * *}$ & $0.029^{* * *}$ \\
\hline $\log \mathrm{GDP}^{2}$ & $0.093^{* * *}$ & $0.010^{* * *}$ & $-0.010^{* *}$ & $0.056^{* * *}$ & $0.005^{*}$ \\
\hline Employment & $0.235^{* * *}$ & $0.264^{* * *}$ & $0.191^{* * *}$ & $0.233^{* * *}$ & $0.140^{* * *}$ \\
\hline Edu/Welfare & $0.060^{* * *}$ & $-0.019^{*}$ & $0.158^{* * *}$ & $0.065^{* * *}$ & $-0.034^{* * *}$ \\
\hline GPRGE & $-0.071^{* * *}$ & $-0.249^{* * *}$ & $-0.078^{* * *}$ & $-0.099^{* * *}$ & $-0.039^{* * *}$ \\
\hline Social capital & $0.206^{* * *}$ & $0.224^{* * *}$ & $0.205^{* * *}$ & $0.222^{* * *}$ & $0.219^{* * *}$ \\
\hline \multicolumn{6}{|l|}{ Value dimensions } \\
\hline Individualism & 0.000 & -0.017 & $0.030^{* *}$ & $0.209^{* * *}$ & -0.009 \\
\hline Individualism $^{2}$ & $0.041^{* * *}$ & $-0.015^{* *}$ & $-0.102^{* * *}$ & $0.157^{* * *}$ & $-0.059^{* * *}$ \\
\hline Masculinity & $0.122^{* * *}$ & $0.112^{* * *}$ & $0.103^{* * *}$ & $0.142^{* * *}$ & $0.094^{* * *}$ \\
\hline PDI & $-0.090^{* * *}$ & $-0.105^{* * *}$ & $0.052^{* * *}$ & $-0.080^{* * *}$ & $-0.067^{* * *}$ \\
\hline UAI & $-0.051^{* * *}$ & $-0.059^{* * *}$ & $-0.115^{* * *}$ & $-0.079^{* * *}$ & $-0.049^{* * *}$ \\
\hline LTO & $-0.092^{* * *}$ & $-0.023^{* *}$ & $-0.056^{* * *}$ & $-0.195^{* * *}$ & $-0.016^{*}$ \\
\hline IVR & $0.539^{* * *}$ & $0.553^{* * *}$ & $0.521^{* * *}$ & $0.491^{* * *}$ & $0.559^{* * *}$ \\
\hline \multicolumn{6}{|l|}{ Interaction effects } \\
\hline \multicolumn{6}{|l|}{ IV $x$ demographics } \\
\hline IV $x$ age & -0.005 & $-0.011^{* *}$ & $-0.034^{* * *}$ & 0.001 & $0.016^{* * *}$ \\
\hline IV $x \operatorname{sex}$ & -0.012 & $0.066^{* * *}$ & -0.000 & -0.003 & $0.053^{* * *}$ \\
\hline IV $x$ income level & $-0.052^{* * *}$ & $-0.036^{* * *}$ & $-0.103^{* * *}$ & $-0.073^{* * *}$ & -0.008 \\
\hline IV $x$ education & $0.027^{* * *}$ & -0.006 & 0.003 & $-0.013^{*}$ & $0.021^{* *}$ \\
\hline IV x employed & $0.030^{* * * *}$ & $-0.052^{* * *}$ & 0.019 & $0.042^{* * *}$ & $-0.031^{* *}$ \\
\hline IV x married & $0.030^{* * *}$ & $0.029^{*}$ & $0.108^{* * *}$ & $0.041^{* * *}$ & $-0.085^{* * *}$ \\
\hline
\end{tabular}


Table 7b. Happiness models, with moderating effects

\begin{tabular}{|c|c|c|c|c|c|}
\hline & $\begin{array}{c}\text { Model 2a: } \\
\text { IV }^{\mathrm{a}}=\text { Log GDP }\end{array}$ & $\begin{array}{c}\text { Model 2b: } \\
\text { IV = Employment }\end{array}$ & $\begin{array}{c}\text { Model 2c: } \\
\text { IV= Edu/Welfare }\end{array}$ & $\begin{array}{c}\text { Model 2d: } \\
\text { IV = GPRGE }\end{array}$ & $\begin{array}{c}\text { Model 2e: } \\
\text { IV = Social capital }\end{array}$ \\
\hline \multicolumn{6}{|l|}{ Interaction effects } \\
\hline IV $x$ religious & -0.003 & $-0.085^{* * *}$ & $-0.050^{* * *}$ & $0.028^{* *}$ & -0.016 \\
\hline IV $x$ health & $-0.042^{* * *}$ & $-0.071^{* * *}$ & $-0.087^{* * *}$ & $-0.082^{* * *}$ & -0.022 \\
\hline \multicolumn{6}{|l|}{ IV $x$ national wealth } \\
\hline IV $x \log$ GDP & & 0.009 & $0.044^{* * *}$ & -0.015 & $-0.013^{*}$ \\
\hline \multicolumn{6}{|c|}{ IV $x$ value dimensions } \\
\hline IV $x$ individualism & $-0.148^{* * *}$ & $-0.073^{* * *}$ & $0.127^{* * *}$ & $-0.392^{* * *}$ & $-0.033^{* * *}$ \\
\hline IV $x$ masculinity & $-0.040^{* * *}$ & 0.010 & 0.000 & $-0.064^{* * *}$ & $-0.036^{* * *}$ \\
\hline IV x PDI & $0.042^{* * *}$ & $0.165^{* * *}$ & $0.048^{* * *}$ & $-0.032^{* *}$ & 0.007 \\
\hline IV $x$ UAI & $0.051^{* * *}$ & $-0.124^{* * *}$ & $0.089^{* * *}$ & $0.051^{* * *}$ & 0.004 \\
\hline IV x LTO & $0.054^{* * *}$ & $-0.102^{* * *}$ & $0.032^{* * *}$ & $0.085^{* * *}$ & -0.007 \\
\hline IV $x$ IVR & $-0.081^{* * *}$ & $0.082^{* * *}$ & $-0.070^{* * *}$ & $-0.169^{* * *}$ & $-0.037^{* * *}$ \\
\hline Cut-point: level 1 & $-2.102^{* * *}$ & $-2.171^{* * *}$ & $-2.142^{* * *}$ & $-2.208^{* * *}$ & $-2.123^{* * *}$ \\
\hline Cut-point: level 2 & $0.079^{* *}$ & 0.006 & 0.025 & -0.018 & $0.051^{*}$ \\
\hline Cut-point: level 3 & $2.989^{* * *}$ & $2.914^{* * *}$ & $2.929^{* * *}$ & $2.900^{* * *}$ & $2.949^{* * *}$ \\
\hline Log-likelihood & -170756 & -170813 & -170972 & -170429 & -171253 \\
\hline
\end{tabular}

Note: $N=175639$. Ordinal logistic regression, with robust standard errors. ${ }^{\mathrm{I} I V}=$ the variable involved in interaction with all the other predictors. ${ }^{\mathrm{b}} \mathrm{Among}$ demographic variables, only age is continuous variable; individual income: three-step; individual education: four-step; sex, employed, married, religiosity, and health: binary variables. ${ }^{\mathrm{c}} 1$ = primary incomplete, 2 = primary complete, $3=$ secondary complete, $4=$ tertiary or higher complete. $S E F s=$ national socio-economic factors. Edu/Welfare $=$ national-level factor of education and welfare. GPRGE = governance, political rights, and gender equality. PDI = power distance. UAI = uncertainty avoidance. $\mathrm{LTO}=\mathrm{long} / \mathrm{short}$-term orientation. $\mathrm{IVR}=$ indulgence versus restraint.

${ }^{*} p<.05^{* *} p<.01^{* * *} p<.001$ 
Table 8. Life Satisfaction models, no interaction terms

\begin{tabular}{|c|c|c|c|c|}
\hline & Model 3a & Model 3b & Model 3c & Model 3d \\
\hline \multicolumn{5}{|c|}{ Demographic variables ${ }^{a}$} \\
\hline Age/10 & $-0.057^{* * *}$ & $-0.009^{*}$ & $-0.028^{* * *}$ & $-0.039^{* * *}$ \\
\hline$(\text { Age } / 10)^{2}$ & $0.063^{* * *}$ & $0.065^{* * *}$ & $0.065^{* * *}$ & $0.061^{* * *}$ \\
\hline Sex & $-0.122^{* * *}$ & $-0.161^{* * *}$ & $-0.145^{* * *}$ & $-0.129^{* * *}$ \\
\hline Income level & $0.470^{* * *}$ & $0.490^{* * *}$ & $0.481^{* * *}$ & $0.455^{* * *}$ \\
\hline Education $^{\mathrm{b}}$ & $0.052^{* * *}$ & $0.111^{* * *}$ & $0.093^{* * *}$ & $0.088^{* * *}$ \\
\hline Employed & 0.022 & $0.062^{* * *}$ & $0.054^{* * *}$ & 0.011 \\
\hline Married & $0.392^{* * *}$ & $0.421^{* * *}$ & $0.443^{* * *}$ & $0.429^{* * *}$ \\
\hline Religious & $0.200^{* * *}$ & $0.094^{* * *}$ & $0.121^{* * *}$ & $0.085^{* * *}$ \\
\hline Health & $1.127^{* * *}$ & $1.099^{* * *}$ & $1.075^{* * *}$ & $1.050^{* * *}$ \\
\hline \multicolumn{5}{|l|}{ SEFs } \\
\hline $\log$ GDP & $0.294^{* * *}$ & & $0.214^{* * *}$ & $0.201^{* * *}$ \\
\hline $\log \mathrm{GDP}^{2}$ & $-0.024^{* * *}$ & & 0.000 & $-0.038^{* * *}$ \\
\hline Employment & $0.147^{* * *}$ & & & $0.204^{* * *}$ \\
\hline Edu/Welfare & $-0.350^{* * *}$ & & & $0.021^{*}$ \\
\hline GPRGE & $0.310^{* * *}$ & & & $0.092^{* * *}$ \\
\hline social capital & $0.206^{* * *}$ & & & $0.205^{* * *}$ \\
\hline \multicolumn{5}{|l|}{ Value dimensions } \\
\hline Individualism & & $-0.107^{* * *}$ & $-0.147^{* * *}$ & $-0.184^{* * *}$ \\
\hline Individualism² & & $-0.044^{* * *}$ & $-0.047^{* * *}$ & $-0.050^{* * *}$ \\
\hline Masculinity & & $0.054^{* * *}$ & -0.006 & $0.027^{* * *}$ \\
\hline PDI & & $-0.126^{* * *}$ & $0.021^{* *}$ & $0.043^{* * *}$ \\
\hline UAI & & $-0.157^{* * *}$ & $-0.094^{* * *}$ & $-0.069^{* * *}$ \\
\hline LTO & & $0.125^{* * *}$ & $0.102^{* * *}$ & $0.035^{* * *}$ \\
\hline IVR & & $0.693^{* * *}$ & $0.620^{* * *}$ & $0.576^{* * *}$ \\
\hline Constant & $4.495^{* * *}$ & $4.354^{* * *}$ & $4.399^{* * *}$ & $4.616^{* * *}$ \\
\hline R-squared & .176 & .187 & .193 & .206 \\
\hline
\end{tabular}

Note: $N=174850$. Regression with robust standard errors. ${ }^{\text {a Among demographic variables, only age is continuous }}$ variable; individual income: three-step individual education: four-step; sex, employed, married, religiosity, and health: binary variables. ${ }^{\mathrm{b}} 1$ = primary incomplete, $2=$ primary complete, $3=$ secondary complete, $4=$ tertiary or higher complete. $\mathrm{SEFs}=$ national socio-economic factors. Edu/Welfare $=$ national-level factor of education and welfare. GPRGE= governance, political rights, and gender equality. $\mathrm{PDI}=$ power distance. $\mathrm{UAI}=$ uncertainty avoidance. $\mathrm{LTO}=\mathrm{long} / \mathrm{short}-$ term orientation. IVR $=$ indulgence versus restraint.

${ }^{*} p<.05^{* *} p<.01 * * * 0.001$

For better interpretation of the findings, the terms are classified as strong when the absolute value of the raw coefficient is .30 or above, moderate when it ranges from .15 to .30 , weak when it ranges from .05 to .15 , and close-to-zero when it is below .05 . On the other hand, when the effect is strong or moderate, it will be considered to be substantial.

Among interaction effects, only those whose absolute value of effect size is over .05 in the same direction both for LS and happiness will be discussed. Otherwise, too many interaction effects will be unnecessarily discussed without need, including theoretically irrelevant and nonrobust ones. 
Table 9a. Life Satisfaction models, with cross-contextual effects

\begin{tabular}{|c|c|c|c|c|c|}
\hline & $\begin{array}{c}\text { Model 4a: } \\
\mathrm{IV}^{\mathrm{a}}=\text { Log GDP }\end{array}$ & $\begin{array}{l}\text { Model 4b: IV = } \\
\text { Employment }\end{array}$ & $\begin{array}{c}\text { Model 4c: } \\
\text { IV = Edu/Welfare }\end{array}$ & $\begin{array}{c}\text { Model 4d: } \\
\text { IV = GPRGE }\end{array}$ & $\begin{array}{c}\text { Model 4e: } \\
\text { IV = Social capital }\end{array}$ \\
\hline \multicolumn{6}{|l|}{ Main effects } \\
\hline \multicolumn{6}{|l|}{ Demographic variables ${ }^{b}$} \\
\hline Age/10 & $-0.034^{* * *}$ & $-0.045^{* * *}$ & $-0.031^{* * *}$ & $-0.037^{* * *}$ & $-0.036^{* * *}$ \\
\hline$(\text { Age } / 10)^{2}$ & $0.059^{* * *}$ & $0.061^{* * *}$ & $0.063^{* * *}$ & $0.057^{* * *}$ & $0.061^{* * *}$ \\
\hline Sex & $-0.142^{* * *}$ & $-0.136^{* * *}$ & $-0.141^{* * *}$ & $-0.140^{* * *}$ & $-0.131^{* * *}$ \\
\hline Income level & $0.484^{* * *}$ & $0.448^{* * *}$ & $0.467^{* * *}$ & $0.483^{* * *}$ & $0.463^{* * *}$ \\
\hline Education $^{c}$ & $0.093^{* * *}$ & $0.103^{* * *}$ & $0.101^{* * *}$ & $0.087^{* * *}$ & $0.097^{* * *}$ \\
\hline Employed & 0.016 & 0.008 & 0.003 & $0.032^{* *}$ & 0.010 \\
\hline Married & $0.433^{* * *}$ & $0.418^{* * *}$ & $0.421^{* * * *}$ & $0.436^{* * *}$ & $0.418^{* * *}$ \\
\hline Religious & $0.080^{* * *}$ & $0.118^{* * *}$ & $0.082^{* * * *}$ & $0.067^{* * * *}$ & $0.092^{* * *}$ \\
\hline Health & $1.041^{* * *}$ & $1.028^{* * *}$ & $1.036^{* * *}$ & $1.028^{* * *}$ & $1.035^{* * *}$ \\
\hline \multicolumn{6}{|l|}{ SEFs } \\
\hline Log GDP & $0.447^{* * *}$ & $0.223^{* * *}$ & $0.249^{* * *}$ & $0.277^{* * *}$ & $0.198^{* * *}$ \\
\hline $\log \mathrm{GDP}^{2}$ & $0.032^{* * * *}$ & $-0.050^{* * *}$ & $-0.095^{* * *}$ & -0.003 & $-0.037^{* * *}$ \\
\hline Employment & $0.348^{* * *}$ & $0.321^{* * *}$ & $0.190^{* * *}$ & $0.304^{* * *}$ & $0.188^{* * *}$ \\
\hline Edu/Welfare & $0.114^{* * *}$ & 0.017 & $0.056^{*}$ & $0.060^{* * *}$ & $0.029^{* *}$ \\
\hline GPRGE & $0.053^{* * * *}$ & $-0.069^{* * *}$ & $0.043^{* * * *}$ & 0.041 & $0.089^{* * *}$ \\
\hline Social capital & $0.213^{* * *}$ & $0.218^{* * *}$ & $0.201^{* * *}$ & $0.219^{* * *}$ & $0.280^{* * *}$ \\
\hline \multicolumn{6}{|l|}{ Value dimensions } \\
\hline Individualism & $-0.181^{* * *}$ & $-0.135^{* * *}$ & $-0.191^{* * *}$ & $0.094^{* * *}$ & $-0.173^{* * *}$ \\
\hline Individualism $^{2}$ & 0.002 & $-0.035^{* * *}$ & $-0.120^{* * *}$ & $0.231^{* * *}$ & $-0.044^{* * *}$ \\
\hline Masculinity & $0.038^{* * *}$ & $0.016^{* *}$ & $0.044^{* * *}$ & $0.088^{* * *}$ & $0.029^{* * *}$ \\
\hline PDI & $0.075^{* * *}$ & $-0.029^{* *}$ & $0.057^{* * *}$ & 0.013 & $0.031^{* * *}$ \\
\hline UAI & $-0.112^{* * *}$ & $-0.063^{* * *}$ & $-0.049^{* * *}$ & $-0.099^{* * *}$ & $-0.059^{* * *}$ \\
\hline LTO & $-0.053^{* * *}$ & $0.029^{* * *}$ & 0.015 & $-0.175^{* * *}$ & $0.038^{* * *}$ \\
\hline IVR & $0.533^{* * *}$ & $0.625^{* * *}$ & $0.577^{* * * *}$ & $0.473^{* * *}$ & $0.574^{* * *}$ \\
\hline \multicolumn{6}{|l|}{ Interaction effects } \\
\hline \multicolumn{6}{|l|}{ IV $x$ demographics } \\
\hline IV $x$ age & 0.003 & -0.005 & $-0.032^{* * *}$ & $0.025^{* * *}$ & $0.029^{* * *}$ \\
\hline IV $x$ sex & -0.003 & $0.080^{* * *}$ & -0.011 & 0.018 & $0.055^{* * *}$ \\
\hline IV $x$ income level & $-0.090^{* * *}$ & $-0.068^{* * *}$ & $-0.053^{* * *}$ & $-0.131^{* * *}$ & $-0.026^{* * *}$ \\
\hline IV $x$ education & $-0.036^{* * *}$ & $-0.019^{* *}$ & $-0.031^{* * *}$ & $-0.035^{* * *}$ & $0.032^{* * *}$ \\
\hline IV x employed & 0.003 & $-0.033^{* *}$ & -0.013 & $0.030^{* *}$ & -0.012 \\
\hline
\end{tabular}


Table 9b. Life Satisfaction models, with cross-contextual effects

\begin{tabular}{|c|c|c|c|c|c|}
\hline & $\begin{array}{c}\text { Model 4a: } \\
\mathrm{IV}^{\mathrm{a}}=\text { Log GDP }\end{array}$ & $\begin{array}{l}\text { Model 4b: IV = } \\
\text { Employment }\end{array}$ & $\begin{array}{c}\text { Model 4c: } \\
\text { IV = Edu/Welfare }\end{array}$ & $\begin{array}{c}\text { Model 4d: } \\
\text { IV = GPRGE }\end{array}$ & $\begin{array}{c}\text { Model 4e: } \\
\text { IV = Social capital }\end{array}$ \\
\hline \multicolumn{6}{|l|}{ Interaction effects } \\
\hline \multicolumn{6}{|l|}{ IV $x$ demographics } \\
\hline IV $x$ married & $0.046^{* * * *}$ & 0.010 & $0.051^{* * * *}$ & $0.068^{* * *}$ & $-0.079^{* * *}$ \\
\hline IV $x$ religious & 0.001 & $-0.035^{* *}$ & $0.077^{* * *}$ & 0.002 & $-0.082^{* * *}$ \\
\hline IV $x$ health & $0.031^{* * * *}$ & -0.006 & $0.076^{* * * *}$ & $0.066^{* * * *}$ & $-0.056^{* * *}$ \\
\hline \multicolumn{6}{|l|}{ IV $x$ national wealth } \\
\hline IV $x \log$ GDP & & $-0.126^{* * *}$ & $0.222^{* * *}$ & $0.064^{* * *}$ & $-0.069^{* * *}$ \\
\hline \multicolumn{6}{|l|}{ IV $x$ value dimensions } \\
\hline IV $\mathrm{x}$ individualism & $-0.041^{* * *}$ & 0.009 & $0.149^{* * *}$ & $-0.525^{* * *}$ & $-0.066^{* * *}$ \\
\hline IV x masculinity & $-0.120^{* * *}$ & $0.079^{* * * *}$ & $-0.077^{* * *}$ & $-0.167^{* * *}$ & -0.003 \\
\hline IV $x$ PDI & $-0.075^{* * *}$ & $0.148^{* * *}$ & 0.018 & $-0.207^{* * *}$ & $-0.070^{* * *}$ \\
\hline IV x UAI & $0.229^{* * *}$ & $-0.185^{* * *}$ & $0.207^{* * *}$ & $0.238^{* * *}$ & $-0.050^{* * *}$ \\
\hline IV x LTO & $-0.048^{* * *}$ & $0.031^{* * * *}$ & $-0.104^{* * *}$ & $-0.024^{* *}$ & $0.121^{* * *}$ \\
\hline IV $x$ IVR & $-0.231^{* * *}$ & $0.207^{* * *}$ & $-0.085^{* * *}$ & $-0.254^{* * *}$ & -0.015 \\
\hline Constant & $4.599^{* * *}$ & $4.632^{* * * *}$ & $4.585^{* * *}$ & $4.589^{* * *}$ & $4.606^{* * *}$ \\
\hline R-squared & .228 & .214 & .217 & .223 & .211 \\
\hline
\end{tabular}

Note: $N=174850$. Regression with Robust Standard Errors. aIV = Variable which is involved in interaction with all the other predictors. ${ }^{\mathrm{b}}$ Among demographic variables, only age is continuous variable; individual income: three-step ordinal ; individual education: four-step ordinal; sex, employed, married, religiosity, and health: binary categorical variables. ${ }^{c} 1$ = primary incomplete, $2=$ primary complete, $3=$ secondary complete, $4=$ tertiary or higher complete. SEFs $=$ national socio-economic factors. Edu/Welfare $=$ national-level factor of education and welfare. GPRGE = governance, political rights, and gender equality. PDI = power distance. UAI = uncertainty avoidance. $\mathrm{LTO}=$ long/short-term orientation. $\mathrm{IVR}$ $=$ indulgence versus restraint.

${ }^{*} p<.05^{* *} p<.01^{* * *} p<.001$ 


\subsection{Demographic variables' main effect}

\subsubsection{Age}

For happiness, the linear coefficient of age ranged from -.08 to -.11 , while for LS it ranged from -.06 to zero. Meanwhile, the quadratic term was between .05 and .06 for happiness, and between 0.057 and .065 for LS. Besides, the grand mean of age was 41.61 years for the happiness sample and 41.63 years for the LS sample. When all those are counted, its polynomial effect in happiness models reverses from negative to positive at a turning point between 49 and 51 years old, and in LS models reverses at a point between 42 and 46 years old. Compared with previous studies that found age's nonlinear effects, the turning points in the present analyses are at a relatively older age ${ }^{8}$.

\subsubsection{Sex}

The variable's main coefficient was, whether moderate or weak, around -.15 for both happiness and LS, replicating the female's advantage in SWB.

\subsubsection{Religiousness}

The effect of religiousness was moderately positive in all happiness models except model $2 \mathrm{~d}$, and weakly positive in all LS models where value dimensions were included. Its positive association with SWB was replicated, but the difference in its effect size for happiness and LS can be explained by its different functions for SWB. According to Okulicz-Kozaryn (2010), religiosity's social aspects, like church attendance and events participation, are associated with LS. Individual facets like belief in god's importance, meanwhile, are more linked with deprived people's consolation and alleviating life misery, and eventually with happiness (Campbell, Converse, \& Rodgers, 1976, p. 370). While both individual and social aspects of religiosity are supported, the present analysis shows that the former is more important for SWB than the latter.

\subsubsection{Marital status}

The strong association between being married and SWB was replicated, with coefficients ranging from .39 to .45 in all LS models, and coefficients ranging from .51 to .60 in all happiness models. According to Nock (2005), being married has three advantages for SWB' : (a) easier social success by signalling maturity and sociability, (b) efficiency in domestic labors, and (c) a more selfrestrained attitude in terms of domestic life and mutual care, leading to improved health. Among those three aspects, (a) and (b) seem more related to LS, because they reflect more objective life conditions than happiness does.

Meanwhile, mutual cares and restraints are not so reflective of LS, and seem more able to be linked to happiness. With the strong effect of marital status for both LS and happiness, all those three aspects seem significant.

\subsubsection{Employment status}

\footnotetext{
8 In Alesina et al. (2004), the polynomial effect reversed at 39.3 years old for a U.S. sample and 44.1 for a European sample. While Helliwell (2002) asserted that SWB was the lowest in 35-44 years old group, also in Kim (2011) the turning point was around 40 years old; and in Tavits (2008) where turning point was 48-50 years old. In all previous studies with nonlinearity the age's polynomial effect, direction changes at the age point between mid-30s and mid-40s old.

9 In his paper, Nock mentioned only happiness, not LS. In my view, however, what he called happiness seems actually to be overall SWB, because many of marriage's advantages he stated are related to materialistic success, and thus also connectable with LS and the ladder of life, instead of happiness.
} 
Contrary to expectation, the direction of the effect of being employed for happiness turned negative in all models. It turned positive for LS, but was non-significant in all full models except model $4 \mathrm{~d}$. Since both positive and negative effects were below .10, it would be fair to say that the present analyses found no effect of employment status. While it would be also nonsensical to say that being unemployed is beneficial for happiness, the present analyses suggest that having a job does not of itself mean a lot for SWB; what matters is not the job itself but its quality.

\subsubsection{Individual education}

Individual-level education's effect was significant but close-to-zero in all happiness full models except model $1 \mathrm{~b}$, and weak in all LS models. While education's small effect is partially attributable to the models' inclusion of higher income, health, and higher trust, through which its indirect effect flows (Helliwell, 2002, p. 11), the present study confirms that education's other aspects like self-realization of potential and freedom (Sen, 2001) have limited effects on SWB. On the other hand, education's contribution to SWB might have been offset by negative elements like failure to meet the high expectation in job seeking (Brennan, Durazzi, \& Séné, 2013, p. 74), or stresses coming from excessive academic competition (Park \& Huebner, 2005).

On the other hand, there is need to compare the results with previous studies where education's effect was found to be strong even after controlling for its indirect effect through income and health (Feasel, 2013; Helliwell \& Putnam, 2004; Helliwell, 2008; Roca, 2011; SalinasJiménez et al., 2010; Tavits, 2008; Tsai et al., 2011). All those studies coded education into dummy variables with the lowest level of education (primary education or lower) as the reference category, while the present study treats it as a continuous variable. If the education variable were categorical, treating it as a continuous variable would be obviously wrong. In both the aforementioned previous studies and in this study, however, education has been the ordinal variable. To address it in regression models, it should be recoded into dummy variables or should be treated as continuous variable. In this case, I would like to argue that this conventional way of setting multiple dummies with the lowest level of education might be problematic in terms of validity.

This is especially for sufficiently developed countries, for the following reasons. First, in most developed countries there are very few who do not finish primary education. In such societies, being at the lowest educational level would be a kind of social stigma, because it is very unusual. Slightly lower education than average might not be a significant disadvantage, but an education level far below might be a serious disadvantage. This means that effect of the lowest education (not just low education) is likely to be damaging. Accordingly with the lowest education as reference category, the dummy variables' effects represent the comparison between the majority in a normal condition and the few in an unusually bad condition. On the contrary, there is no such hazard of inflation when education is treated as a continuous variable.

My additional analyses prove my conjecture above. I conducted a full model approach for happiness again, but this time I coded the education variable into dummy variables, varying in the level of reference category. Table 10 below demonstrates that the appearance of dummy coefficients is largely altered by reference category level. All three dummy effects were reported to be substantial and significant, when lowest education was the baseline (model 5b). However, two of them lost significance when the reference category was changed to higher levels of education (model 5c and 5d). Similarly, in model series 6 with trinomial education variable, tertiary or higher education's effect lost its significance when the reference category level was raised from the lowest to the middle level (compare model $6 a$ and $6 \mathrm{~b}$ ). 
Table 10. Education's category steps, reference category levels, and their influence on its effect for happiness.

\begin{tabular}{lcccccc}
\hline \multirow{2}{*}{ REFCAT $^{\mathbf{y}}$} & Model 5a & Model 5b & Model 5c & Model 5d & Model 6a & Model 6b \\
\cline { 2 - 6 } & & $\mathbf{1 / 4}$ & $\mathbf{2 / 4}$ & $\mathbf{3 / 4}$ & $\mathbf{1 / 3}$ & $\mathbf{2 / 3}$ \\
\hline No dummy & $0.043^{* * *}$ & & & & $-0.040^{* * *}$ \\
Education level: 1 & & & $-0.192^{* * *}$ & $-0.202^{* * *}$ & & $0.040^{* * *}$ \\
Education level: 2 & & $0.192^{* * *}$ & & -0.009 & $0.056^{* * *}$ & 0.016 \\
Education level: 3 & & $0.202^{* * *}$ & 0.009 & & \\
Education level: 4 & & $0.219^{* * *}$ & 0.027 & 0.017 & & -171440 \\
Log-likelihood & -171426 & -171396 & -171396 & -171396 & -171440 &
\end{tabular}

Note: $N=175639$. Log GDP, four national social factors, and six Hofstede value dimensions were included in all models, but not presented in the table. ${ }^{a}$ REFCAT $=$ the level of reference category in respect to the number of category steps; for instance, 1/4 means that the reference category was the lowest level (which means value one), while the education variable was of four categories. When the category was of four-step scale, 1 = primary education incomplete; $2=$ primary complete, secondary incomplete; $3=$ secondary complete; $4=$ tertiary or higher degree complete. When the category was of three-step levels, 1 = secondary education incomplete; 2 = secondary complete; 3 = tertiary or higher degree complete.

${ }^{*} p<.05^{* *} p<.01^{* * *} p<.001$

According to those results, education effects have been inflated by the previous convention of setting dummy variables with the lowest level of education as the reference category. When middle-level education was set as the reference category (model $5 c$, $5 d$, and $6 b$ ), meanwhile, the dummy effects in overall are similar to the results of my original analyses, where education was treated as a continuous variable. In my view, this is enough to suggest that taking education as a continuous variable is more favorable to precise effects estimation, than dummy analyses with the lowest education as reference category.

\subsubsection{Individual income}

While previous studies differed in the significance of individual income effects, such significance was fully supported in the present analyses. Meanwhile, its effect was stronger in LS full models $(r=.44-.50)$, than in happiness full models (.27-.30); this is in line with the argument that LS reflects more materialistic aspects than does happiness (Haller \& Hadler, 2006; Helliwell, Huang, et al., 2009), but my finding shows that even for happiness affluence is substantially important.

\subsubsection{Health}

In the present analyses, the strong and robust effect of health was replicated, with a coefficient over 1.00 in all models for happiness and LS. Furthermore, no SEF robustly moderated health, meaning that the strong association between health and SWB is universal, rather than varied by national contexts.

\subsection{SEFs' main effects}

\subsubsection{National wealth}

In all models without log GDP's interaction terms (model series 1 and 2b-2e), logged GDP's effect for SWB was weak or close-to-zero for happiness and moderate for LS. Controlling its interactions, however, its influence became moderate for happiness (model 2a, coefficient .184) and strong for LS (model 4a, coefficient .447). National wealth's greater effect for LS than for happiness is in line with Haller \& Hadler (2006) and Helliwell, Barrington-Leigh, Harris, \& 
Huang (2009)'s argument that LS reflects more aspects of evaluating material conditions than does happiness.

Meanwhile, the quadratic effect was positive in all happiness models except model 2c, while in the model series 4 for LS its direction was varied. Therefore, I found no evidence for national affluence's diminishing marginal effect. Taken together, while the present analyses confirm national affluence's relevance only for LS, I found no evidence supporting the hypothesis of diminishing marginal effect.

\subsubsection{National employment factor}

In LS full models, national employment factors' effect ranged from .18 to .35, while its effect for happiness ranged from .14 to .25. Studies by Flavin et al. (2010) and Abbott and Wallace (2012) only have dealt with labor union density's relationship with LS. While no previous study addressed the relationship with happiness, the present study suggests that its importance is greater for LS than for happiness. While the path from labor union density to SWB can be explained by its function of raising the worker's collective autonomy (Edwards, 1979), and boosting workplace participation (Fenwick \& Olson, 1986), the present analyses suggest that such an outcome is crucial for LS but its relevance is relatively limited to emotional SWB (happiness). This is contrasted with organization participation that is a part of social capital—while happiness and LS are associated with social capital to a similar degree, social capital's effect for happiness is greater than that of national employment factor (Table 6 above). This implies that participation in a labor union differs in nature from general social participation.

While previous studies differed in the significance of national employment rate and labor union density, the present study fortifies their importance for SWB. Meanwhile, the substantial effects of social capital components (mainly trust and membership) are simply in line with their robust association with SWB in previous studies. While social capital is often equated with social relationship (Agampodi, Agampodi, Glozier, \& Siribaddana, 2015; Kim, Lee, \& Yoon, 2014; Salomons, 2006; Yang, Yuan, \& Wang, 2008), or considered to be a core concept of it (McKnight, Teaster, Watkins, \& Lawrence., 2005; Moscardo, 2007; Risal, 2008, 2013; Schrader, 2004), the present study suggests that the social relation is equally important for happiness and LS.

\subsubsection{Edu/Welfare}

When it comes to the effect of Edu/Welfare, which consists of four variables - education expenditure, enrolment, inequality, and public social expenditure - I found little evidence for its association with SWB. In model 1a and 3a the effect was strongly negative, and only in model 4 a it was positive with coefficient size over .10. Overall, the factor's relevance was relatively less than that of other SEFs. Taken together, the present analyses do not find its firm association with happiness or LS.

The finding of the relatively weak importance of Edu/Welfare components is in line with previous ones, where the association between inequality and SWB has been varied and no significantly positive effect of national education has been found. Besides, the negative sides of education (another component of the Edu/Welfare factor), like competitiveness and failure to meet higher expectations, also held at the national level.

\subsubsection{GPRGE}

Like the Edu/Welfare factor, GPRGE's relevance for SWB was found to be weak. Its coefficient, around +.30 in models $1 \mathrm{a}$ and $3 \mathrm{a}$, turned weak for most other LS models, and reversed to negative 
for all the happiness models. In any case, the present paper does not support governance, gender equality, and political rights' firm association with SWB. This is in line with most previous studies where democracy and gender equality remained non-significant.

Regarding the weak or non-significant effect of democracy, one of the GPRGE's components, I have stated that adaptation theory and comparison effect cannot be sufficient explanations because all national social factors should have weak or non-significant effects. A more probable explanation is that while GPRGE has been often conceptually linked with intellectual autonomy (Inglehart \& Welzel, 2010; Kabanoff, 1991; Lea, 2000; Sørensen, 1997, 1998), GPRGE's effect would be undermined if intellectual autonomy is not necessarily beneficial for SWB.

Counter-intuitively, intellectual autonomy has its own cost. First, it might be associated with more social isolation. The closest relationships around us are based on a certain degree of common cognitive paths (Leins, Fisher, Pludwinski, Rivard, \& Robertson, 2014, p. 327). In that case, intellectual independence might cause more distance between the self and others around him(her) due to differences in ways of thinking. A similar argument has been already made by Durkheim's classical work in sociology (1951). Accordingly, Protestants' higher rate of suicide was explained by the world view of Protestant religion that allows more differences and freedoms in thought. Additionally, while an appropriate level of autonomy is needed for economic freedom, gratification, and satisfaction, further increase in choice can cause its own side effects like excessive search costs, post-decision regret (Binswanger, 2006; Desmeules, 2002; Hsee, Hastie, \& Chen, 2008; Hsee \& Hastie, 2006; Schwartz, 2010), and information overload (Caprara, Barbaranelli, Pastorelli, Bandura, \& Zimbardo, 1999; Iyengar \& Lepper, 2000). Those possible drawbacks of intellectual autonomy could provide explanations for the weak effect of GPRGE, which represents its social conditions, along with that of the limited effect of individualism, which is another parameter of autonomy in the cultural realm.

\subsubsection{Social capital}

The effect of social capital was around .20 in the all models, both for happiness and LS. Along with employment, social capital's effect was the highest of all SEFs. With its similar degree of effect for happiness and LS, it is suggested that both the emotional outcome of social participation (happiness) and network favoring an individual's success (the factor for LS) are equally relevant.

\subsection{Value dimensions' main effects}

Among the four original Hofstede dimensions, only UAI's negative effect was fully in line with most previous studies. Meanwhile, I found LTO's negative effect, and strong association between IVR and SWB.

\subsubsection{Individualism}

In all happiness models except model $2 \mathrm{~b}$ and $2 \mathrm{~d}$, the turning point of individualism's polynomial effect was between -.2 and +.2 , all of which can be considered within the moderate level ${ }^{10}$ (Table 11 below).

At first glance, this might seem to support the previous argument that the effect is optimal at the moderate level of individualism. However, it should be remembered that when the quadratic term is positive, the graph would show the contrary; the polynomial effect is at its lowest at the turning point, given that the effect keeps decreasing until that point and only changes to an

\footnotetext{
${ }^{10}$ For happiness and life satisfaction's listwise sample, the median value of individualism was -0.022 and -0.023 respectively.
} 
increasing effect above that point. In turn, the quadratic effects' direction was not fully consistent across the present happiness models. All other models, except models $2 \mathrm{a}$ and $2 \mathrm{~d}$, showed a negative quadratic term, but the positive quadratic effect in model $2 \mathrm{~d}$ was too strong to be ignored (Table 7 above). Therefore, the present analyses do not robustly confirm any of the previous arguments regarding individualism-happiness association.

This means that the majority of sample units fall above the turning point (Table 11 below), suggesting that the total polynomial effect turned out to be negative for most of sample countries. In models $3 b, 3 c, 3 d, 4 b, 4 c$, and $4 e$, the quadratic term was negative, suggesting that at the turning point the polynomial function's direction changes from increasing to decreasing. In those models, meanwhile, the turning point were at an extremely low level or at least below the low quartile.

If the quadratic term is negative and the turning point is low, then the total effect (the sum of quadratic and linear coefficient) would be negative for the majority of sample countries which are above the turning point.

In such functions, the function effect is positive only for the few units with an even lower level of individualism, and for the majority the polynomial effect would be always negative. With positive quadratic terms, the total effect is positive when the predictor's level is above the turning point. In the model $4 \mathrm{a}$, however, the turning point level was above the maximum level ${ }^{11}$, and therefore individualism's total effect is obviously negative for all subject countries. In sum, in all LS full models except model $4 \mathrm{~d}$, individualism's negative aspects are supported.

Taken together, while the association between individualism and happiness was unclear, the analyses on LS were plainly inclined to individualism's dark aspects. These findings on individualism's effect are largely at odds with previous findings, which were more inclined to its contributing aspects. To explain the inconsistency in findings, I conducted additional analyses to see whether the effect was largely affected by variation in controlled variables. Table 12 below reveals that, among other value dimensions, IVR's inclusion made individualism's potential positive effect disappear for happiness, and reversed to negative for LS. In other words, the large reduction in individualism's effect is due to IVR's inclusion in the present analyses. This can be theoretically explained in relation to two separate dimensions of autonomy, which have been distinguished by Schwartz (1994). Schwartz distinguished two types of autonomy-intellectual autonomy, referring to the independent pursuit of one's own ideas and intellectual directions, and affective autonomy, referring to the independent pursuit of positive experience like pleasure, excited-ness, and a varied life. Here, it should be remembered that I have already stated some reasons for the weak effect of intellectual autonomy when describing on GPRGE's effects.

\footnotetext{
${ }^{11}$ In the LS sample, the highest observed value of standardized individualism was 2.815 , but the turning point in model 4a was 57.113.
} 
Table 11. Individual's polynomial effect patterns' variation across model series 1-4

\begin{tabular}{|c|c|c|c|c|c|c|c|}
\hline \multirow{2}{*}{ Dependent variable } & \multirow{2}{*}{$\begin{array}{c}\text { Model } \\
\text { No. } \\
\end{array}$} & \multirow{2}{*}{$\begin{array}{c}\text { Quadratic } \\
\text { term }^{\text {b }}\end{array}$} & \multicolumn{4}{|c|}{ Turning point ${ }^{\mathrm{a}}$} & \multirow{2}{*}{ Polynomial effect's shape } \\
\hline & & & Value & $N$ below $^{c}$ & $\mathbf{P} \%{ }^{d}$ & Location $^{\mathrm{e}}$ & \\
\hline \multirow[t]{8}{*}{ Happiness } & Model 1b & $(-)(-)$ & -0.115 & 85177 & 48.50 & Near the median & Highest at moderate level $^{\mathrm{f}}$ \\
\hline & Model 1c & $(-)(-)$ & -0.188 & 83690 & 47.65 & Near the median & Highest at moderate level \\
\hline & Model 1d & $(-)(-)$ & -0.123 & 85177 & 48.50 & Near the median & Highest at moderate level \\
\hline & Model 2a & $(+)$ & -0.006 & 89583 & 51.00 & Near the median & Lowest at moderate level \\
\hline & Model 2b & $(-)$ & -0.575 & 50628 & 28.83 & Low-middle & Close to negative linear effects \\
\hline & Model 2c & $(-)(-)(-)$ & 0.146 & 93232 & 53.08 & Near the median & Highest at moderate level \\
\hline & Model 2d & $(+)(+)(+)$ & -0.666 & 45065 & 25.66 & Just above the 1st quartile & Close to positive linear effect \\
\hline & Model 2e & $(-)(-)$ & -0.079 & 85177 & 48.50 & Near the median & Highest at moderate level \\
\hline \multirow[t]{8}{*}{ Life Satisfaction } & Model 3b & $(-)(-)$ & -1.206 & 31138 & 17.73 & Below the 1st quartile & Close to negative linear effect \\
\hline & Model 3c & $(-)(-)$ & -1.580 & 8830 & 5.05 & Near the lowest extreme & Close to negative linear effect \\
\hline & Model 3d & $(-)(-)$ & -1.833 & 2466 & 1.41 & Near the lowest extreme & Close to negative linear effect \\
\hline & Model 4a & $(+)$ & 57.113 & 174850 & 100.00 & Above the highest value & Close to negative linear effect \\
\hline & Model 4b & $(-)$ & -1.936 & 2466 & 1.41 & Near the lowest extreme & Close to negative linear effect \\
\hline & Model 4c & $(-)(-)(-)$ & -0.795 & 43386 & 24.81 & Below the 1st quartile & Close to negative linear effect \\
\hline & Model 4d & $(+)(+)(+)$ & -0.204 & 80868 & 46.25 & Near the median & Lowest at moderate level \\
\hline & Model 4e & $(-)(-)$ & -1.978 & 2466 & 1.41 & Near the lowest extreme & Close to negative linear effect \\
\hline
\end{tabular}

Note: For happiness sample, $N=175639$; for life satisfaction sample, $N=174850$. ${ }^{\text {aTurning }}$ point $=$ the predictor's value point where the polynomial effect's direction changes. $\mathrm{b}(-)(-)(-)$ :negative, below -.10; $(-)(-)$ : negative, from -.10 to $-.05 ;(-)$ : negative but above $-.05 ;(+)$ : zero or positive, from .00 to $.05 ;(+)(+)$ : from .05 to $.10 ;(+)(+)(+)$ : positive and above .10 . $^{c}$ The number of observations with individualism level below the turning point. dit refers to within-sample percentile of turning point's individualism score. ${ }^{\text {eWhen }}$ the turning point is far from the mid-point, it is more likely that most countries have the same direction of polynomial effects - that explains the need to specify turning point's sketchy location, through comparison with maximum, minimum, and median values of standardized individualism; in happiness sample, Min. = -2.062 , median = -0.022, Max. $=2.823$; in life satisfaction sample, Min. $=-2.059$, median $=-0.023$, Max. $=2.815 .{ }^{\mathrm{f}}$ At moderate level means when the individualism's level is moderate. $\mathrm{g}$ The polynomial is actually very similar to negative linear effect, either because turning point was near the lowest value and above that point the polynomial function kept decreasing, or because turning point was near the highest value and only above that point the function began to increase, applying to very few countries. 
Table 12. Individualism's effect for SWB's variation, by the controlled value dimension variables

\begin{tabular}{llllllc}
\hline \multirow{2}{*}{ Controlled value dimensions } & \multicolumn{3}{c}{ Happiness models } & \multicolumn{2}{c}{ Life Satisfaction models } \\
\cline { 2 - 7 } & Model No. & B & Log-likelihood & $\begin{array}{l}\text { Model } \\
\text { No. }\end{array}$ & B & $\begin{array}{c}\text { R- } \\
\text { squared }\end{array}$ \\
\hline None & Model 7a & $0.151^{* * *}$ & -178927 & Model 8a & $0.217^{* * *}$ & .118 \\
MAS & Model 7b & $0.146^{* * *}$ & -178898 & Model 8b & $0.207^{* * *}$ & .119 \\
MAS, PDI & Model 7c & $0.104^{* * *}$ & -178849 & Model 8c & $0.086^{* * *}$ & .122 \\
MAS, PDI, UAI & Model 7d & $0.061^{* * *}$ & -178667 & Model 8d & $0.011^{* *}$ & .126 \\
MAS, PDI, UAI, LTO & Model 7e & $0.156^{* * *}$ & -177530 & Model 8e & $0.106^{* * *}$ & .135 \\
MAS, PDI, UAI, LTO, IVR & Model 7f & $-0.031^{* * *}$ & -173322 & Model 8f & $-0.119^{* * *}$ & .182 \\
\hline
\end{tabular}

Note: Ordinal logistic regression for happiness, and general regression for life satisfaction; both with robust standard errors. $N$ for happiness sample $=179337 ; N$ for life satisfaction sample $=178564$. MAS = masculinity; PDI = power distance; $\mathrm{UAI}=$ uncertainty avoidance; $\mathrm{LTO}=$ long/short-term orientation; IVR = Indulgence vs. Restraint. Linear effect of individual-level demographic variables including age, sex, three-step income level, four-step education, employment status, marital status, religiosity, and health were included in all models but are not displayed in the table.

${ }^{*} p<.05^{* *} p<.01^{* * *} p<.001$

Comparing Schwartz and Hofstede's value systems, Schwartz's affective autonomy is similar to Hofstede's IVR, in that both relate to cultural endorsement of pleasure-seeking behaviors. Therefore, controlling IVR's effect in the model, individualism no longer counts the affective autonomy. While individualism has been discussed often in association with autonomy (Diener et al., 1999; Diener \& Suh, 1997; Larsen \& Eid, 2008), when IVR effect is controlled individualism's autonomous aspect is limited to intellectual autonomy. Further, it should be remembered that, except Minkov (2009), no previous study has co-included individualism and IVR for SWB models. In my view, this would explain individualism's having a far smaller effect than those found in previous studies. Individualism's effect is no longer inflated because, while previously it covered both affective and intellectual autonomy, in the present study it covers only intellectual autonomy, which is not a main contributor to SWB.

\subsubsection{Masculinity}

Contrary to Basabe et al.'s (2000) argument, masculinity effect was positive in all models for both LS and happiness. While masculine culture's negative effect was not replicated, its positive effect for LS was close-to-zero in all full models except in model $4 \mathrm{~d}$, and for happiness it was weak in all full models. Taken together, the present findings differ from previous arguments, but they are not remarkable enough to allow new arguments to be suggested. To be more certain of masculine/feminine culture's association with SWB, further studies are needed.

\subsubsection{PDI}

As expected, PDI effects for happiness were negative. None of them, however, was to the substantial degree. In all LS full models except model $4 b$, its effects were rather positive, significant or not. While the effect was close-to-zero in model $4 \mathrm{~d}$ and $4 \mathrm{e}$, the coefficient became above +.05 in model $4 \mathrm{a}$ and 4c. With some theoretical grounds, those results can be interpreted as a challenge to the high PDI's dysfunction theory, which has been firmly argued in previous studies, including Basabe et al.'s (2000) paper. It is theoretically possible that, in certain societies, the high PDI culture might bring its own benefits. Hierarchy makes individual members feel 
more stable and facilitates within-group coordination (Magee \& Galinsky, 2008, p. 5). Accordingly, in my view, since higher PDI means more widespread acceptance of the hierarchy, it might contribute to stability in social relationship.

Likewise, it is also possible that low PDI be detrimental in some societies. Here it should be remembered that the definition of low PDI regards little acceptance of hierarchy, not necessarily egalitarianism. PDI may be low not only in egalitarian societies, but also in Hobbesian societies where everyone struggles for power with no controlling authority, eventually degrading social SWB. In any case, further studies should consider more possibilities for PDI's effects on SWB, including my conjectures.

\subsubsection{UAI}

Among four original Hofstede dimensions, only UAI's effect was plainly replicated, in line with previous arguments. Its effect was significantly negative in all models for both happiness and LS though the degree was weak or close-to-zero.

\subsubsection{LTO}

LTO's effect for happiness turned negative whenever social quality factors were included (model $1 \mathrm{~d}$ and model series 2). In full models for LS, the LTO's effect direction was varied but all effects above close-to-zero in degree were negative. Overall, the present models are inclined to LTO's negative aspects. While Hofstede (2001) defined LTO as "the fostering of virtues oriented towards future rewards, in particular, perseverance and thrift" (p. 359), it seems that the emphasis on the future and success do not contribute to SWB.

\subsubsection{IVR}

Unlike the effects of all other value dimensions, the influence of IVR on SWB was consistently overwhelming. With effects always above or around .50 in all models, along with marital status and health, its effect for SWB held the most powerful explanatory power.

This finding is in line with Minkov (2009), who found the importance of IVR was predominant, while most of the other effects were non-significant. He suggested that replication is needed because the WVS sample covers only a few countries in miserable conditions. However, I do not agree with his point. To quote the expression of Triandis (2000, p. 31), sufficiently many 'vulnerable' societies were included in the WVS (e.g. Belarus, Iran, Kyrgyzstan); even Iraq has been surveyed in the WVS no less than three times (in 2004, 2006, and 2012). In any case, the predominant influence of IVR is not a byproduct of sampling bias, and the present study confirms indulgence's robust and overwhelming effect on SWB.

\subsection{Demographic variables' moderation by SEFs}

As a result of introducing national social effects' moderating effects, many interaction effects recorded in previous studies have been altered. While Bonini (2007), Helliwell (2008), and Swift et al. (2014)'s moderating effect of sex, individual income, and marital status by cultural zones were transferred to moderating effects by non-economic social factors, the interaction effects involving age, individual education, and religiosity disappeared; furthermore, the positive moderation of individual income by national income in Bonini (2007) was reversed to negative. Likewise, the moderation of national social factors by national income in previous studies disappeared, being replaced by value dimensions. 


\subsubsection{Low individual income: national wealth, Edu/Welfare, and GPRGE}

No less than three national factors - log GDP, Edu/Welfare, and GPRGE - interacted with low individual income. The Edu/Welfare and GPRGE's moderation suggests, in societies mature in the level of democracy, gender equality, governance, and welfare system, the deprived people are less disadvantaged. Meanwhile, the log GDP's negative moderation suggests that the meaning of individual's relative poverty differs between rich and poor nations - being relatively poor in affluent countries might be merely a matter of economic dissatisfaction, but in poor countries it is a matter of survival.

\subsubsection{Male gender: by national employment factor and social capital}

In model $2 \mathrm{~b}$ and $4 \mathrm{~b}$, national employment factor moderated the male sex. This can be explained by the fact that in most countries, in reality, the male is more responsible for getting a job and providing food for the family. Therefore, males are more likely to be concerned.

In model $2 \mathrm{e}$ and $4 \mathrm{e}$, social capital moderated the male sex, which can be explained by gender difference in political participation and interests, which are parts of social capital components. In fact, it has been repeatedly found that "compared to women, men are more knowledgeable about and more interested in politics and more likely to feel politically efficacious (Verba, Burns, \& Schlozman, 1997, p. 1051)", for reasons like women's disadvantage in access to information sources, the difference in social roles, and men's aggressiveness and taste for conflict.

\subsubsection{Marital status: Edu/Welfare and social capital factor}

Models 2c and 4c show that married peoples get more benefit when the national education/welfare system level is better. This can be explained by two facts. First, the welfare system of most societies is centered on household units. Since households are mostly formed through marriage, this means that those married, all of who have their own family, are generally in a more favorable position as welfare system beneficiaries. The same holds for education. For those married and with children, national education is important because it is related to the burden of their children's education as a part of their domestic affairs.

Opposite to Edu/Welfare, social capital factor negatively moderated marriedness. That is, the single (unmarried) get more benefits from social capital than the married. In societies with a low level of social capital, the unmarried or the single will have more difficulties in accessing opportunities for social interactions out of the home. For the same people in high-level social capital countries, on the contrary, the increase in social memberships can buffer possible loneliness and social isolation.

\subsection{Interactions between National Wealth and Social Quality}

No social quality factor interacted with wealth with coefficient over .05 both for happiness and LS.

\subsection{Value dimensions' moderation of SEFs}

\subsubsection{IVR's negative interactions with national wealth, Edu/Welfare, and GPRGE}

While IVR's interaction with the national employment factor (model $2 \mathrm{~b}$ and $4 \mathrm{~b}$ ) should be dealt with in subsequent studies, IVR also negatively interacted with national wealth, $\mathrm{Edu} /$ Welfare, and GPRGE. That is, the effect of a high indulgence culture is greater in countries which are low in national affluence, education, governance, equality, and political freedom. 
Such interaction between IVR and low social development seems to suggest that the nature of IVR, in certain aspects, is of evasive pleasure. This becomes more obvious when we focus on the negative interaction between equality/democracy/governance (GPRGE) and IVR. In many socio-politically oppressive societies (low GPRGE), people are often given the chance to console themselves through leisure, sports, or entertainment that is supported by the non-democratic government, with aims to appease people's discontent. Actually, most dictatorial regimes sponsor sports or entertainment (Tunis, 1935) ${ }^{12}$. In my view, a similar argument can be made for IVR's interaction with low Edu/Welfare and low national wealth. When people are poor and unprotected by society, they keep more to their current pleasure because they do not have hope for the future ${ }^{13}$. In this sense, IVR's effect for SWB partially reflects some aspects of SWB whose nature is closer to blind happiness, which was argued by Graham (2009).

\subsubsection{Edu/Welfare's interaction with individualism and UAI}

For both LS and happiness, the Edu/Welfare factor was moderated by individualism in models 2c and 4c, to a moderate degree. According to Adelman (1988), Cohen and Avrahami (2006), and Kim and McKenry (1998), the development of institutional welfare reduces the community need for mutual informal support. This suggests that the effect of welfare for SWB will be less in collectivistic societies, where according to Kim \& McKenry (1998) the informal support is more emphasized. To put it in another way, welfare effect will be higher in the individualistic culture than in the collectivistic one, which explains the robust interactions between individualism and Edu/Welfare factor.

In models $2 \mathrm{c}$ and $4 \mathrm{c}$, the Edu/Welfare factor was also moderated by UAI, for both happiness and LS. Moderation by UAI can be explained by the reality that in societies where people are more prone to subjective security, perceived risks and uncertainties, current wealth becomes important to relieve anxiety.

\subsubsection{National employment factor by PDI and low UAI}

In models $2 b$ and $4 b$, beside being moderated by IVR, the national employment factor was also moderated by PDI and low UAI. The moderating effect of low UAI is worth discussion in relation to the work environment. According to Wennekers, Thurik, Stel, \& Noorderhaven (2007), large companies in high UAI societies have a more restrictive climate than those in low UAI societies, lowering satisfaction in the work environment.

Furthermore, employees of such companies are more worried about their future, suffering high job stress, fear of failure, lower ambition for individual advancement and pessimism about motives (Arrindell et al., 1997, p. 42). While Arrindell et al. associated those negative characteristics only with UAI's main effects, the present study relates those factors with not only UAI's negative main effects, but also the lower priority of national employment in high UAI societies. A probable explanation for this is that getting a job (higher employment factor) is less meaningful in high UAI societies because their cultural traits demotivate workers.

Meanwhile, PDI's moderation on national employment can be explained with two factors. One is that employedness has more meanings in high PDI societies than in the others-in high PDI culture, having a job should be understood not only in terms of self-realization, but also in

\footnotetext{
12 For instance, Spain's former Franco regime's support for soccer, (Xifra, 2008, p. 194), Nazi Germany's effort to hold successful Olympic games (Murray, 1992), Korea's Chun Doo-Hwan government's deep interest in sports (Kim, 2008). ${ }^{13}$ Actually, poverty and hedonism are often stated together (e.g. Brasseaux, 1989, p. 3; Castillo \& Beilock, n.d.; Debnath \& Mondal, 2014, p. 658)
} 
terms of fulfilling responsibility for their family (Hwa-Froelich \& Vigil, 2004). From the perspective of corporate organizations, in turn, companies in high PDI cultures are likely to adopt a seniority system, and this would add to importance of early job-getting in order to secure the future. In my view, this adds to the importance of being employed in high PDI countries, and this possibility explains the interaction between high PDI and national employment.

\subsubsection{GPRGE's negative interaction with individualism and masculinity}

In models $2 \mathrm{~d}$ and $4 \mathrm{~d}$, GPRGE negatively interacted with individualism, to the strongest degree among all interaction terms for both happiness and LS. Statistically, this finding seems to support that in individualistic cultures higher GPRGE becomes more detrimental to SWB. Theoretically, however, there is not any ground to support that interpretation. Since both are related to intellectual autonomy, rather, it would be more valid to interpret the negative interaction as that GPRGE and individualism are mutual substitutes, and therefore when one's level increases, the other one's need decreases ${ }^{14}$.

Meanwhile, GPRGE interacted with feministic culture (low masculinity), weakly for happiness and moderately for LS (model $2 \mathrm{~d}$ and $4 \mathrm{~d}$ ). Its possible explanation is that the quality of life is more valued in a feministic culture, while it is facilitated by developed GPRGE.

In the same models, GPRGE also interacted with UAI, weakly for happiness but substantially for LS. The moderation effect of UAI can be explained by relating governance (one component of GPRGE) with the ability to handle people's subjective uncertainty, a similar argument to the one developed by Schramm-Nielsen (2000), who compared social causes of the degree of UAI in Denmark with that of France. Regarding Denmark's lower UAI culture than that of France, they explained with two factors; (a) Danish organizational rules which explicitly allows more deviances, and endows more autonomy for subordinates, and (b) factors discouraging people from seeking permanent security in the same company (e.g. historical familiarity with high job mobility and rarity in internal promotions). They considered those elements as a part of state capacity, to deal with subjective uncertainty. Considering state capacity's conceptual association with governance, which is part of GPRGE, their arguments provide indirect explanations for the interaction between GPRGE and UAI's interaction. In other words, it can be said that governance is important for reducing/relieving the uncertainty in daily life, in order to prevent perceived uncertainty's saturation going beyond a tolerable level, and for allowing individuals to freely handle it.

\section{Implications and Concluding Remarks}

Using WVS panel data covering 1981 to 2013 for 59 countries, the present research aimed to explore SWB determinants in greater detail, in three ways. First, this study took the full-model approach, analyzing joint effect of broad ranged economic, social, and cultural variables. Second, the present paper also extended the cross-contextual approach by introducing new types of moderation effects. Additionally, the present study took into account recent cultural changes in Hofstede's value dimensions, for more valid measurement of the relationship between value dimensions and SWB.

With those methods of interpretation, I could explain far richer findings than those hitherto discussed. While not all the new findings confirm the previous findings and existing SWB theories, they could be explained with the following four ways of interpretation.

\footnotetext{
${ }^{14}$ Interpreting negative interaction as a mutually substituting relationship is not a completely new idea. The same approach was also taken by Hanson (2015, p. 13), who discussed democracy and state capacity.
} 
The first way is to focus on the individual/social needs regulated by national cultural values and individuals' demographic traits, which in turn determines the relative importance of different predictors. For instance, I have specified that the more collectivistic the country is, the less beneficial the national welfare system is. Likewise, by stating the higher priority of jobseeking and political participation, I could explain the moderating effects involving the male sex.

The second way of interpretation is to focus on the analyzed variables' meaning for an individual's personal life and social/organizational relationship. For instance, taking account of religiousness and marital status's multi-faceted utilities, their effects on LS and happiness could be clarified.

The third way of interpretation is to relate predictors with abstract values - for instance, autonomy. Those values could not be and had not been operationalized quantitatively. However, their theoretical links with SWB have been discussed in previous studies, creating clues about the effect of related predictors in the present analyses. For instance, the autonomy-SWB relationship was able to be related to the present findings on the degree of individualism, GPRGE, and IVR's effects.

The last way of interpretation was the more methodological one-confounding effects and robust estimation.

This method was used especially for interpreting many of the present findings that differ from the previous ones. For instance, I have shown that uncontrolling IVR effects could cause inflation of individualism effects. Likewise, when the hypothesis of national wealth's diminishing marginal effects was rejected, I explained that by confounding with national wealth's interaction with social factors.

It should be noted that with comprehensive analyses on SWB determinants, the present study revealed coherent effect patterns by variable types, as follows. First, with income level's substantial effects, both for happiness and LS and both at individual and national level, the present study confirms the relevance of material conditions for SWB. Meanwhile, the predominant effect of social capital and marital status confirms the importance of social relationship and connectedness. Additionally, the strong effect of IVR shows that temporary pleasure is more influential for both happiness and LS than has been hitherto considered. Conversely, I could not find strong association between social progress and SWB, despite the presence of its theoretical arguments in Heylighen \& Bernheim (2001) and Yee \& Chang (2009); among four social quality factors, Edu/Welfare and GPRGE seem to be the most closely related to social progress, but in the present study their effects were far from being remarkable.

\subsection{Future research}

\subsubsection{Limitations of the present study}

The present research's limitations are as follows. First, the present study did not consider a global sample. Although I have stated that vulnerable countries were sufficiently counted in the present study's sample, still the proportion between developed and underdeveloped countries (23 countries from OECD and 36 from non-OECD) does not match the proportions found in the real world.

Furthermore, despite that the present study substantially extended the range of crosscontextual effects, there are still more to be explored - for instance, cultural values' moderation on demographic variables. Furthermore, national contexts affecting demographic effects are themselves, in reality, a combination of economy, society, and culture. It might be possible that, for instance, that individual education's effect is moderated by the national wealth, and in turn this moderating effect is affected by national PDI level. National factors themselves mutually 
interact, while at the same time influencing individual variables' relevance to SWB. While Ciftci (2010, p. 145) found that the SWB consequence of democracy development is varied by each country's existing cultural and institutional schemes, the same can apply to other non-economic social factors. This fortifies the significance of analyzing moderating effects that are more complex, beyond two-dimensional interactions. For instance, the three-dimensional interaction between PDI, national wealth, and individual-level gender will show another picture of the SWB mechanism. Even when considering only national-level variables, exploring multi-order interactions (e.g. welfare effect's variation, across combination models of national wealth and PDI culture) will enrich cross-contextual approaches to determinants of SWB.

Furthermore, while I used Hofstede dimensions as parameters of culture, there are far more cultural domains whose contexts deserve further researches. For further clarification of the SWB mechanism, prospective studies should examine contexts defined by other cultural domains than Hofstede dimensions. Among those alternative cultural domains, the most familiar one for SWB researchers would be the cultural zone. Dealing with the cultural zone's contexts would be far more intricate than doing with value dimensions' contexts. The nature of value dimensions is assumed to be constant over time, and its defined attributes often tell some possible social consequences by themselves. For instance, we do not have to always know Korea or Spain's histories or traditions, in order to understand high UAI culture's social functions in those countries. To explore cultural zones contexts, on the contrary, we will have to understand any socio-cultural changes that might have affected value priorities for SWB. That means we have to look at the whole history of that culture, even when we use a rough approach to the culturespecific determinants for SWB. Those difficulties, however, do not deny the need to explore contexts of other cultural domains than value dimensions, for full understanding of contextual approach in SWB determinants.

Besides, effect coherence by variable types suggests the need for further discussion of the nature of SWB. This is related to two subjects: the prevalence of pleasure-seeking effects, and the degree of conceptual equivalence between social progress and SWB.

Hitherto, debates on the nature of SWB have been represented by two distinct viewpoints_-pleasure-centered hedonism and virtue-centered eudaimonism (Ryan \& Deci, 2001; Waterman, 1993). In the present study, the pleasure-related variables exerted a coherently strong effect for not only happiness but also for LS, whose nature is rather eudaimonic than hedonistic (Bünger, 2010; Proctor, Tweed, \& Morris, 2014). Thus, the present findings are plainly inclined to the hedonistic viewpoint. By extension, it also suggests the possibility that the pleasure-seeking attitude's role might be crucial, even more than hitherto discussed in SWB research.

Contrary to pleasure-related variables, the effect of social progress turned out to be weak even for eudaimonic LS (Bünger, 2010; Proctor et al., 2014), indicating the discrepancy between social progress and SWB. While various researchers see SWB as an equivalent of social progress or as its direct outcome (e.g. D'Acci, 2010; McClean, 2014; Plé, 2000; Veenhoven, 2008; Veenhoven \& Kalmijn, 2005), the present findings do not confirm such a stance. Of course, the present study alone is not enough for complete rejection of their conceptual proximity-not confirming is not the same as rejection. In prospective analyses with a worldwide or more proportionate sample, the social progress effects might be larger than in the present findings. Furthermore, even if social effects are weak in overall, SWB still can be used to evaluate the social outcome of policies; we can still evaluate each social domain's relative effects for SWB, and find the relevant and effective policies that are connected with social domains having remarkable effects.

At the least, however, the present study does suggest the need for re-discussion of the conceptual relationship between social progress and SWB. Here, it is worth stating two main 
stances on the nature of social progress-universalistic and cultural relativistic views. In the universalistic view, the criterion and nature of social progress is universal, and should be applied equally across cultures (e.g. Follett, 1998; Spencer, 1895). Accordingly, social progress factors' measurement should be cross-culturally varied, and this makes it unfeasible to analyze the effect of standardized social progress factors for a multi-cultural sample. The universalistic view, therefore, supports that social progress and SWB are heterogeneous concepts, and thus they should be taken separately.

Cultural relativists, in turn, argue that the current concept of social progress has been formed in the Western tradition, and therefore it should not be forced on to other cultures (e.g. Çaylak, 2008; Riegg, 2007, p. 3). Accordingly, since the definition of social progress is varied across cultures, in the cross-cultural sample studies it cannot be measured in a consistent way. Thus, it will be harder to test social progress and SWB's conceptual equivalence or unrelated-ness. In this case, to continue exploring the conceptual links between social progress and SWB, our frameworks of social progress should allow for constituting indicators that are partially varied across cultures. Either universalism or cultural relativism is adapted, the present study casts doubt on the viewpoint that SWB should be understood in the frame of social progress. Above all, the effect patterns in the present study are too coherent to be disregarded.

\section{Acknowledgement}

I would like to thank three professors of Seoul National University: Prof. Jaeyeol Yee, for his concern with my statistical rigorousness; , Prof. Dukjin Chang, for having been my teacher of sociological foundations; Prof. Inchul Choi, for his interest in my research despite disciplinary difference and my own earlier inexperiences. I am also grateful to Daewook Kim, PhD student of sociology, for having encouraged me to pay attention to happiness studies.

\section{Author}

Ki-Hoon Jun

Seoul National University

siskoih7@snu.ac.kr

\section{Publishing Timeline}

Received 2 February 2015

Accepted 25 August 2015

Published 18 December 2015

\section{References}

Abbott, P., \& Wallace, C. (2012). Social Quality: A way to measure the quality of society. Social Indicators Research, 108(1), 153-167. http://dx.doi.org/10.1007/s11205-011-9871-0

Adelman, M. B. (1988). Cross-cultural adjustment: A theoretical perspective on social support. International Journal of Intercultural Relations, 12(3), 183-204. http://dx.doi.org/10.1016/0147$\underline{1767(88) 90015-6}$

Agampodi, T. C., Agampodi, S. B., Glozier, N., \& Siribaddana, S. (2015). Measurement of social capital in relation to health in low and middle income countries (LMIC): A systematic review. Social Science $\mathcal{E}$ Medicine, 128, 95-104. http://dx.doi.org/10.1016/j.socscimed.2015.01.005

Alesina, A., Di Tella, R., \& MacCulloch, R. (2004). Inequality and happiness: are Europeans and Americans different? Journal of Public Economics, 88(9-10), 2009-2042. http://dx.doi.org/10.1016/j.jpubeco.2003.07.006

Allik, J., \& McCrae, R. R. (2004). Toward a geography of personality traits: Patterns of profiles across 36 cultures. Journal of Cross-Cultural Psychology, 35(1), 13-28. http://dx.doi.org/10.1177/0022022103260382 
Arrindell, W. A., Hatzichristou, C., Wensink, J., \& Rosenberg, E. (1997). Dimensions of national culture as predictors of cross-national differences in subjective well-being. Personality and Individual Differences, 23(1), 37-53. http://dx.doi.org/10.1016/S0191-8869(97)00023-8

Argyle, M. (1997). Is happiness a cause of health? Psychology and Health, 12(6), 769-781. http://dx.doi.org/10.1080/08870449708406738

Basabe, N., Paez, D., Valencia, J., Rimé, B., Pennebaker, J., Diener, E., \& González, J. L. (2000). Sociocultural factors predicting subjective experience of emotion: A collective level analysis. Psicothema, 12, 55-69.

Beck, W. (2001). Social quality: a vision for Europe (Vol. 7). Kluwer Law International.

Binswanger, M. (2006). Why does income growth fail to make us happier? Searching for the treadmills behind the paradox of happiness. Journal of Socio-Economics, 35(2), 366-381. http://dx.doi.org/10.1016/j.socec.2005.11.040

Bjørnskov, C. (2008). How comparable are the Gallup World Poll life satisfaction data? Journal of Happiness Studies, 11(1), 41-60. http://dx.doi.org/10.1007/s10902-008-9121-6

Bjørnskov, C., Dreher, A., \& Fischer, J. A. (2008). Cross-country determinants of life satisfaction: Exploring different determinants across groups in society. Social Choice and Welfare, 30(1), 119-173. http://dx.doi.org/10.1007/s00355-007-0225-4

Bjørnskov, C., Fischer, J. A. V., \& Dreher, A. (2007). On gender inequality and life satisfaction: Does discrimination matter? SSE/EFI Working Paper Series in Economics and Finance, No. 657. http://dx.doi.org/10.2139/ssrn.980629

Blanchflower, D. G. (2008). International evidence on well-being. IZA Discussion Papers No. 3354.

Blanchflower, D. G., \& College, D. (2005). Happiness and the Human Development Index: The paradox of Australia. Australian Economic Review, 38(3), 307-318. http://dx.doi.org/10.1111/j.14678462.2005.00377.x

Bonini, A. N. (2007). Cross-national variation in Individual Life Satisfaction: Effects of national wealth, human development, and environmental conditions. Social Indicators Research, 87(2), 223-236. http://dx.doi.org/10.1007/s11205-007-9167-6

Brasseaux, C. A. (1989). Four hundred years of Acadian life in North America. The Journal of Popular Culture, 23(1), 3-22. http://dx.doi.org/10.1111/j.0022-3840.1989.2301 3.x

Brennan, J., Durazzi, N., \& Séné, T. (2013). Things we know and don't know about the Wider Benefits of Higher Education : A review of the recent literature. BIS Research Paper No. 133.

Bünger, B. (2010). The demand for relational goods: Empirical evidence from the European Social Survey. International Review of Economics, 57(2), 177-198. http://dx.doi.org/10.1007/s12232-010-0094-5

Camfield, L. (2012). Quality of life in developing countries. In K. C. Land, A. C. Michalos, \& M. J. Sirgy (Eds.), Handbook of social indicators and quality of life research (pp. 399-432). Springer Science \& Business Media. http://dx.doi.org/10.1007/978-94-007-2421-1

Camfield, L., Guillen-Royo, M., \& Velazco, J. (2009). Does needs satisfaction matter for psychological and subjective wellbeing in developing countries: A mixed-methods illustration from Bangladesh and Thailand. Journal of Happiness Studies, 11(4), 497-516. http://dx.doi.org/10.1007/s10902-009-9154-5

Campbell, A., Converse, P. E., \& Rodgers, W. L. (1976). The quality of American life: Perceptions, evaluations, and satisfactions. Russell Sage Foundation. http://dx.doi.org/10.1017/S0008423900050976

Caprara, G. V., Barbaranelli, C., Pastorelli, C., Bandura, A., \& Zimbardo, P. G. (1999). Comparison, grouping, and preference. Psychological Science, 10(3), 225-229. http://dx.doi.org/10.1111/14679280.00141

Castillo, M. J., \& Beilock, R. (2004). Selling their best for little: The riddle of Ecuador's failed attempt to assist communal farmers. Revista Latinoamericana de Desarrollo Economico, 2, 123-142.

Çaylak, A. (2008). Autocratic or democratic? A critical approach to civil society movements in Turkey. Journal of Economic and Social Research, 10(1), 115-151.

Ciftci, S. (2010). Modernization, Islam, or social capital: What explains attitudes toward democracy in the Muslim world? Comparative Political Studies, 43(11), 1442-1470.

http://dx.doi.org/10.1177/0010414010371903 
Clark, A. (2003). Inequality-aversion and income mobility: A direct test. DELTA Working Paper No. 2003-11.

Clark, A. E., \& Senik, C. (2010). Will GDP growth increase happiness in developing countries? PSE Working Paper No.2010-43.

Cohen, A., \& Avrahami, A. (2006). The relationship between individualism, collectivism, the perception of justice, demographic characteristics and organisational citizenship behaviour. The Service Industries Journal, 26(8), 889-901. http://dx.doi.org/10.1080/02642060601011707

Cushman, P. (1990). Why the self is empty. Toward a historically situated psychology. The American Psychologist, 45(5), 599-611. http://dx.doi.org/10.1037/0003-066X.45.5.599

D'Acci, L. (2010). Measuring well-being and progress. Social Indicators Research, 104(1), 47-65. http://dx.doi.org/10.1007/s11205-010-9717-1

Debnath, G. C., \& Mondal, P. (2014). Effects of ecogeomorphological parameters on environment : Case study of Birbhum District, West Bengal. International Journal of Innovative Research and Studies, 3(3), 654-667.

Desmeules, R. (2002). The impact of variety on consumer happiness : Marketing and the tyranny of freedom. Academy of Marketing Science Review, 2002(July), 1-18.

Diaz-Serrano, L., \& Rodríguez-pose, A. (2012). Decentralization, subjective well-being, and the perception of institutions. Kyklos, 65(2), 179-193. http://dx.doi.org/10.1111/j.1467-6435.2012.00533.x

Diener, E., Oishi, S., \& Lucas, R. E. (2003). Personality, culture, and subjective well-being: Emotional and cognitive evaluations of life. Annual Review of Psychology, 54, 403-25. http://dx.doi.org/10.1146/annurev.psych.54.101601.145056

Diener, E., \& Suh, E. (1997). Measuring quality of life: Economic, social, and subjective indicators. Social Indicators Research, 40(1), 189-216. http://dx.doi.org/10.1023/A:1006859511756

Diener, E., Suh, E. M., Lucas, R. E., \& Smith, H. L. (1999). Subjective well-being: Three decades of progress. Psychological Bulletin, 125(2), 276-302. http://dx.doi.org/10.1037//0033-2909.125.2.276

Durkheim, E. (1951). Suicide: A study in sociology (JA Spaulding \& G. Simpson, trans.). Glencoe, IL: Free Press.(Original Work Published 1897).

Edwards, R. (1979). Contested terrain: The transformation of the workplace in the twentieth century. New York: Basic Books.

Feasel, E. M. (2013). Understanding Subjective Well-Being across countries : Economic, cultural and institutional factors. International Review of Social Sciences and Humanities, 5(1), 67-85.

Fenwick, R., \& Olson, J. (1986). Support for worker participation: Attitudes among union and non-union workers. American Sociological Review, 51(4), 505. http://dx.doi.org/10.2307/2095584

Fischer, J. A. (2010). Accounting for unobserved country heterogeneity in happiness research: Country fixed effects versus region fixed effect. MPRA Paper No. 22272.

http://dx.doi.org/10.2139/ssrn.1618212

Fischer, R., \& Boer, D. (2011). What is more important for national well-being: Money or autonomy? A meta-analysis of well-being, burnout, and anxiety across 63 societies. Journal of Personality and Social Psychology, 101(1), 164-184. http://dx.doi.org/10.1037/a0023663

Fischer, R., Vauclair, C.-M., Fontaine, J. R. J., \& Schwartz, S. H. (2010). Are individual-level and countrylevel value structures different? Testing Hofstede's legacy with the Schwartz Value Survey. Journal of Cross-Cultural Psychology, 41(2), 135-151. http://dx.doi.org/10.1177/0022022109354377

Flavin, P., Pacek, A. C., \& Radcliff, B. (2010). Labor unions and life satisfaction : Evidence from new data. Social Indicators Research, 98(3), 435-449. http://dx.doi.org/10.1007/s11205-009-9549-z

Follett, M. P. (1998). The new state: Group organization the solution of popular government. Pennsylvania State University Press. New York: Longman, Green. (Original work published 1917).

George, L. K., \& Landerman, R. (1983). Health and subjective well-being: A replicated secondary data analysis. International Journal of Aging \& Human Development, 19(2), 133-156.

http://dx.doi.org/10.2190/FHHT-25R8-F8KT-MAJD

Graham, C. (2009). Happiness around the world: The paradox of happy peasants and miserable millionaires. Contemporary Sociology: A Journal of Reviews (Vol. 40). Oxford University Press. http://dx.doi.org/10.1177/0094306110391764p 
Haller, M., \& Hadler, M. (2006). How social relations and structures can produce happiness and unhappiness: An international comparative analysis. Social Indicators Research, 75(2), 169-216. http://dx.doi.org/10.1007/s11205-004-6297-y

Hanson, J. (2015). Democracy and state capacity: Complements or substitutes? Studies in Comparative International Development, 50(3), 304-330. http://dx.doi.org/10.1007/s12116-014-9173-z

Hanssen, M. (2011). Is equality a determinant of well-being?: a cross-national analysis of income inequality and self-reported life satisfaction (Master Thesis). Georgetown University.

Helliwell, J. F. (2002). How's life? Combining individual and national variables to explain subjective well-being. NBER Working Paper No. 9065. http://dx.doi.org/10.1016/S0264-9993(02)00057-3

Helliwell, J. F. (2008). Life satisfaction and quality of development. National Bureau of Economic Research No. 14507. http://dx.doi.org/10.3386/w14507

Helliwell, J. F., Huang, H., \& Harris, A. (2009). International differences in the determinants of life satisfaction. In New and enduring themes in development economics Vol.5 (pp.3-40). World Scientific Publishing Co. Pte. Ltd. http://dx.doi.org/10.1142/9789812839428 0001

Helliwell, J. F., \& Barrington-leigh, C. P. (2010). Viewpoint: Measuring and understanding Subjective Well-Being. Canadian Journal of Economics, 43(3), 729-753. http://dx.doi.org/10.1111/j.15405982.2010.01592.x

Helliwell, J. F., \& Putnam, R. D. (2004). The social context of well-being. Philosophical Transactions of the Royal Society of London. Series B, Biological Sciences, 359(1449), 1435-46. http://dx.doi.org/10.1098/rstb.2004.1522

Helliwell, J. F., Barrington-Leigh, C. P., Harris, A., \& Huang, H. (2009). International evidence on the social context of well-being. NBER Working Paper Series No. 14720. http://dx.doi.org/10.3386/w14720

Helliwell, J. F., Layard, R., \& Sachs, J. (2013). World happiness report. The Earth Insitute, Columbia University.

Heylighen, F., \& Bernheim, J. (2001). Measuring Global Progress through Subjective Well-Being. In Proceedings of the III Conference of the ISQOLS.

Hofstede, G. (2001). Culture's consequences: Comparing values, behaviors, institutions and organizations across nations. Sage Publications, Incorporated.

Hofstede, G., \& McCrae, R. R. (2004). Personality and culture revisited: Linking traits and dimensions of culture. Cross-Cultural Research, 38(1), 52-88. http://dx.doi.org/10.1177/1069397103259443

Hofstede, G. J., \& Jan, G. (2011). Dimensions of national cultures. http://www.geerthofstede.nl

Hofstede, G., \& Minkov, M. (2010). Long- versus short-term orientation: New perspectives. Asia Pacific Business Review, 16(4), 493-504. http://dx.doi.org/10.1080/13602381003637609

Howell, R. T., \& Howell, C. J. (2008). The relation of economic status to subjective well-being in developing countries: A meta-analysis. Psychological Bulletin, 134(4), 536-60. http://dx.doi.org/10.1037/0033-2909.134.4.536

Hsee, C. K., \& Hastie, R. (2006). Decision and experience: Why don't we choose what makes us happy? Trends in Cognitive Sciences, 10(1), 31-37. http://dx.doi.org/10.1016/j.tics.2005.11.007

Hsee, C. K., Hastie, R., \& Chen, J. (2008). Hedonomics: Bridging decision research with happiness research. Perspectives on Psychological Science, 3(3), 224-243. http://dx.doi.org/10.1111/j.17456924.2008.00076.x

Hwa-Froelich, D. A. D. C. V. (2004). Three aspects of cultural influence on communication: A literature review. Communication Disorders Quarterly, 25(3), 107-118. http://dx.doi.org/10.1177/15257401040250030201

Inglehart, R., Foa, R., Peterson, C., \& Welzel, C. (2008). Development, freedom and rising happiness: A global perspective. Psychological Science, 3(4), 264-285. http://dx.doi.org/10.1111/j.17456924.2008.00078.x

Inglehart, R., \& Welzel, C. (2010). Changing mass priorities: The link between modernization and democracy. Perspectives on Politics, 8(02), 551-567. http://dx.doi.org/10.1017/S1537592710001258 
Iyengar, S. S., \& Lepper, M. R. (2000). When choice is demotivating: Can one desire too much of a good thing? Journal of Personality and Social Psychology, 79(6), 995-1006. http://dx.doi.org/10.1037/0022$\underline{3514.79 .6 .995}$

Jorgensen, B. S., Jamieson, R. D., \& Martin, J. F. (2010). Income, sense of community and subjective wellbeing: Combining economic and psychological variables. Journal of Economic Psychology, 31(4), 612623. http://dx.doi.org/10.1016/j.joep.2010.04.002

Joshanloo, M., \& Weijers, D. (in press). Religiosity's moderation effect on the relationship between income inequality and subjective well-being across the globe. Journal of Cross-cultural psychology. http://dx.doi.org/10.1007/s11205-015-1054-y

Kabanoff, B. (1991). Equity, equality, power, and conflict. Academy of Management Review, 16(2), 416-441. http://dx.doi.org/10.5465/AMR.1991.4278961

Kim, B.-C. (2008). Professional baseball in Korea: Origins, causes, consequences and implications. The International Journal of the History of Sport, 25(3), 370-385. http://dx.doi.org/10.1080/09523360701805811

Kim, H. K., \& McKenry, P. C. (1998). Social networks and support: a comparison of African Americans, Asian Americans, Caucasians, and Hispanics. Journal of Comparative Family Studies, 29(2), 313-334.

Kim, N., Lee, D. Y., \& Yoon, W. (2014). Outside director appointment in Korean business groups: The role of stakeholder networks. International Journal of Management and Network Economics, 3(2), 169180. http://dx.doi.org/10.1504/IJMNE.2014.060870

Kim, S. (2011). Sociological studies on happiness in cross-national contexts: effects of economic inequality and marriage (Doctoral Dissertation). The University of Iowa.

Knutsen, C. H. (2008). GDP, inequality, democracy and the happiness of nations. Department of Political Science, University of Oslo.

Larsen, R. J., \& Eid, M. (2008). Ed Diener and the science of Subjective Well-Being. In M. Eid \& R. J. Larsen (Eds.), The science of Subjective Well-Being (pp. 1-13). Guilford Publications.

Lea, D. (2000). Individual autonomy, group self-determination and the assimilation of indigenous cultures. Discussion Paper No. 18.

Leins, D. A., Fisher, R. P., Pludwinski, L., Rivard, J., \& Robertson, B. (2014). Interview protocols to facilitate human intelligence sources' recollections of meetings. Applied Cognitive Psychology, 28(6), 926-935. http://dx.doi.org/10.1002/acp.3041

Licht, A. N., Goldschmidt, C., \& Shalom, H. S. (2007). Culture rules: The foundations of the rule of law and other norms of governance. Journal of Comparative Economics, 35(4), 659-688.

http://dx.doi.org/10.1016/j.jce.2007.09.001

Lonner, W. J., Berry, J. W., \& Hofstede., G. H. (1980). Culture's consequences: International differences in work-related values. University of Illinois at Urbana-Champaign's Academy for Entrepreneurial Leadership Historical Research Reference in Entrepreneurship.

Magee, J. C., \& Galinsky, A. D. (2008). Social hierarchy: The self-reinforcing nature of power and status. Academy of Management Annals, 2(1), 351-398. http://dx.doi.org/10.1080/19416520802211628

McClean, D. D. (2014). National and international indices of well-being: A critical analysis. Journal of Indiana Academy of Social Sciences, 17, 39-55.

McKnight, R., Teaster, P., Watkins, J., \& Lawrence., S. (2005). Occupational choice and vulnerability in late life: An example of women in the USA. In International Congress Series, (Vol. 1280, pp. 106-111). Elsevier. http://dx.doi.org/10.1016/j.ics.2005.02.059

Minkov, M. (2009). Predictors of differences in subjective well-being across 97 nations. Cross-Cultural Research, 43(2), 152-179. http://dx.doi.org/10.1177/1069397109332239

Minkov, M., \& Hofstede, G. (2010). Hofstede's fifth dimension: New evidence from the World Values Survey. Journal of Cross-Cultural Psychology, 43(1), 3-14. http://dx.doi.org/10.1177/0022022110388567

Morrison, M., Tay, L., \& Diener, E. (2011). Subjective well-being and national satisfaction: Findings from a worldwide survey. Psychological Science, 22(2), 166-71. http://dx.doi.org/10.1177/0956797610396224

Moscardo, G. (2007). Analyzing the role of festivals and events in regional development. Event Management, 11(1-2), 23-32. http://dx.doi.org/10.3727/152599508783943255

Murray, B. (1992). Berlin in 1936: Old and new work on the Nazi Olympics. The International Journal of the History of Sport, 9(1), 29-49. http://dx.doi.org/10.1080/09523369208713778 
Nock, S. L. (2005). Marriage as a public issue. The Future of Children, 15(2), 13-32. http://dx.doi.org/10.1353/foc.2005.0019

Oishi, S., Diener, E. F., Lucas, R. E., \& Suh, E. M. (1999). Cross-cultural variations in predictors of life satisfaction: Perspectives from needs and values. Personality and Social Psychology Bulletin, 25(8), 980990. http://dx.doi.org/10.1177/01461672992511006

Okulicz-Kozaryn, A. (2010). Religiosity and life satisfaction across nations. Mental Health, Religion $\mathcal{E}$ Culture, 13(2), 155-169. http://dx.doi.org/10.1080/13674670903273801

Okun, M. a., \& George, L. K. (1984). Physician- and self-ratings of health, neuroticism and subjective well-being among men and women. Personality and Individual Differences, 5(5), 533-539. http://dx.doi.org/10.1016/0191-8869(84)90027-8

Okun, M. A., Stock, W. A., Haring, M. J., \& Witter, R. A. (1983). Health and subjective well-being: A meta-analysis. International Journal of Aging \& Human Development, 19(2), 111-132. http://dx.doi.org/10.2190/QGJN-0N81-5957-HAQD

Ott, J. C. (2008). Happiness, economics and public policy: A critique. Journal of Happiness Studies, 11(1), 125-130. http://dx.doi.org/10.1007/s10902-008-9125-2

Ott, J. C. (2009). Good governance and happiness in nations: Technical quality precedes democracy and quality beats size. Journal of Happiness Studies, 11(3), 353-368. http://dx.doi.org/10.1007/s10902-0099144-7

Park, N., \& Huebner, E. S. (2005). A cross-cultural study of the levels and correlates of life satisfaction among adolescents. Journal of Cross-Cultural Psychology, 36(4), 444-456. http://dx.doi.org/10.1177/0022022105275961

Plé, B. (2000). Auguste Comte on positivism and happiness. Journal of Happiness Studies, 1(4), 423-445. http://dx.doi.org/10.1023/A:1011597222119

Proctor, C., Tweed, R., \& Morris, D. (2014). The naturally emerging structure of well-being among young adults: 'Big Two' or other framework? Journal of Happiness Studies, 1-19. http://dx.doi.org/10.1007/s10902-014-9507-6

Putnam, R. D. (1994). What makes democracy work? National Civic Review, 82(2), 101-107. http://dx.doi.org/10.1002/ncr.4100820204

Putnam, R. D., Leonardi, R., \& Nanetti, R. Y. (1993). Social Capital and Institutional Success. In Making democracy work: Civic traditions in modern Italy (pp. 163-185). Princeton University Press.

Riegg, N. T. (2007). Peace and international security: Meta-theoretical conversations. In Making Sense of A Pluralist World: The Sixth Pan-European Conference on International Relations (pp. 12-15). Turin, Italy.

Risal, S. M. (2008). To buy or not to buy. Boston, MA: Trumpeter.

Risal, S. M. (2013). Experience of adult campers about the summer family camp 2012 in Finland, Lapland (Master's Thesis). University of Lapland.

Roca, T. (2011). Subjective well-being: Easterlin paradox, the (decreasing) return(s)? From log to square, new evidence from wealthier data. SSRN Working Paper Series, No. 163. http://dx.doi.org/10.2139/ssrn.1751686

Rojas, M. (2011). Relative income and well-being in Latin America. Report for the Latin American Research Network of the Inter-American Development Bank. Puebla, Mexico: Facultad Latinoamericana de Ciencias Sociales, Sede México and Universidad Popular Autónoma del Estado de Puebla.

Ryan, R. M., \& Deci, E. L. (2001). On happiness and human potentials: A review of research on hedonic and eudaimonic well-being. Annual Review of Psychology, 52, 141-166. http://dx.doi.org/10.1146/annurev.psych.52.1.141doi:10.1146/annurev.psych.52.1.141

Sacks, D. W., Stevenson, B., \& Wolders, J. (2011). Growth in income and subjective well-being over time. mimeo, University of Michigan.

Sacks, D. W., Stevenson, B., \& Wolfers, J. (2010). Subjective well-being, income, economic development and growth. CESifo working paper: Fiscal Policy, Macroeconomics and Growth, No. 3206. http://dx.doi.org/10.3386/w16441

Salinas-Jiménez, M. D. M., Artés, J., \& Salinas-Jiménez, J. (2010). Education as a positional good: A life satisfaction approach. Social Indicators Research. 103(3), 409-426. http://dx.doi.org/10.1007/s11205-010$\underline{9709-1}$ 
Salomons, K. (2006). The response of two BC sawmill communities to the recession of the early 1980s (Doctoral Dissertation). University of British Columbia.

Schrader, H. (2004). Spheres of trust, social capital and transformation in Russia. Trust and Social Transformation. Theoretical Approaches and Empirical Findings from Russia, 79-102.

Schramm-Nielsen, J. (2000). How to interpret uncertainty avoidance scores: a comparative study of Danish and French firms. 7(4). Cross Cultural Management: An International Journal, 3-11. http://dx.doi.org/10.1108/13527600010797129

Schwartz, B. (2004). The paradox of choice: Why more is less. New York: Ecco.

Schwartz, B. (2010). Be careful what you wish for - The dark side of freedom. In Handbook of the uncertain self (pp. 62-77). Psychology Press.

Schwartz, S. H. (1994). Beyond individualism/collectivism: New cultural dimensions of values. Sage Publications, Inc.

Schyns, P. (1998). Cross-national differences in happiness: Economic and cultural factors explored. Social Indicators Research, 43(1-2), 3-26. http://dx.doi.org/10.1023/A:1006814424293

Sen, A. (2001). Development as freedom. Oxford University Press.

Senik, C. (2004). When information dominates comparison: Learning from Russian subjective panel data. Journal of Public Economics, 88(9-10), 2099-2013. http://dx.doi.org/10.1632/074069503X85526

Snider, P. D. (2003). Exploring the relationships between individualism and collectivism and attitudes towards counselling among Ethnic Chinese, Australian, and American University Students (Doctoral Dissertation). Murdoch University.

Sørensen, E. (1997). Democracy and empowerment. Public Administration, 75(3), 553-567. http://dx.doi.org/10.1111/1467-9299.00074

Sørensen, E. (1998). New forms of democratic empowerment. Introducing user influence in the primary school system in Denmark. Statsvetenskaplig Tidskrift, 101(2).

Spencer, H. (1895). The principles of sociology (Vol. 6). Appleton.

Swift, H. J., Vauclair, C.-M., Abrams, D., Bratt, C., Marques, S., \& Lima, M.-L. (2014). Revisiting the paradox of well-being: The importance of national context. The Journals of Gerontology. Series B, Psychological Sciences and Social Sciences, 1-10. http://dx.doi.org/10.1093/geronb/gbu011

Taras, V., Steel, P., \& Kirkman, B. L. (2012). Improving national cultural indices using a longitudinal meta-analysis of Hofstede's dimensions. Journal of World Business, 47(3), 329-341. http://dx.doi.org/10.1016/j.jwb.2011.05.001

Tavits, M. (2008). Representation, corruption, and Subjective Well-Being. Comparative Political Studies, 41(12), 1607-1630. http://dx.doi.org/10.1177/0010414007308537

Tov, W., \& Diener, E. (2008). The well-being of nations: Linking together trust, cooperation, and democracy. In B. A. Sullivan, M. Snyder, \& J. L. Sullivan (Eds.), Cooperation: The political psychology of effective human interaction (pp. 323-342). Malden, MA: Blackwell.

Triandis, H. C. (2000). Cultural syndromes and Subjective Well-being. In E. Diener \& E. M. Suh (Eds.), Culture and subjective well-being (pp. 13-36). MIT Press.

Tsai, M.-C., Chang, H.-H., \& Chen, W. (2011). Globally happy: Individual globalization, expanded capacities, and Subjective Wellbeing. Social Indicators Research, 108(3), 509-524. http://dx.doi.org/10.1007/s11205-011-9890-x

Tunis, J. R. (1936). The dictators discover sport. Foreign Affairs, 14(4), 606-617. http://dx.doi.org/10.2307/20030762

Veenhoven, R. (2008). Sociological theories of Subjective Well-Being. In M. Eid \& R. Larsen (Eds.), The science of Subjective Well-being: A tribute to Ed Diener (pp. 44-61). New York: Guilford Publications.

Veenhoven, R., \& Kalmijn, W. (2005). Inequality-adjusted happiness in nations egalitarianism and utilitarianism married in a new index of societal performance. Journal of Happiness Studies, 6, 421-455. http://dx.doi.org/10.1007/s10902-005-8857-5

Verba, S., Burns, N., \& Schlozman, K. L. (1997). Knowing and caring about politics: Gender and political engagement. The Journal of Politics, 59(4), 1051-1072. http://dx.doi.org/10.2307/2998592 
Waterman, A. S. (1993). Two conceptions of happiness: Contrasts of personal expressiveness (eudaimonia) and hedonic enjoyment. Journal of Personality and Social Psychology, 64(4), 678-691. http://dx.doi.org/10.1037/0022-3514.64.4.678

Weijers, D., \& Joshanloo, M. (in press). Religiosity buffers and has a quadratic moderation effect on the relationship between gender inequality and life satisfaction around the world. Social Indicators Research.

Welzel, C., \& Inglehart, R. (2010). Agency, values, and well-being: A human development model. Social Indicators Research, 97(1), 43-63. http://dx.doi.org/10.1007/s11205-009-9557-z

Wennekers, S., Thurik, A. R., Stel, A. Van, \& Noorderhaven, N. (2007). Uncertainty avoidance and the rate of business ownership across 21 OECD countries, 1976-2004. Journal of Evolutionary Economics, 17(2), 133-160. http://dx.doi.org/10.1007/s00191-006-0045-1

Xifra, J. (2008). Soccer, civil religion, and public relations: Devotional-promotional communication and Barcelona Football Club. Public Relations Review, 34(2), 192-198. http://dx.doi.org/10.1016/j.pubrev.2008.03.005

Yang, P., Yuan, Z., \& Wang, N. (2008). The mechanism for social capital influence on the growth of regional economy: An analysis based on networking model. Human Geography, 5, 18.

Yee, J., \& Chang, D. (2009). Social quality as a measure for social progress. In Proceedings of The 3rd OECD World Forum on "Statistics, Knowledge and Policy" - Charting Progress, Building Visions, Improving Life Busan, Korea. 